\title{
Meniscal Repair and Transplantation: Indications, Techniques, Rehabilitation, and Clinical Outcome
}

\author{
Timothy P. Heckmann, PT, ATC ${ }^{1}$ \\ Sue D. Barber-Westin, $B S^{2}$ \\ Frank R. Noyes, $M D^{3}$
}

\begin{abstract}
The purpose of this paper is to provide current knowledge regarding the indications, operative techniques, rehabilitation programs, and clinical outcomes of meniscus repair and transplantation procedures. Meniscus tears that occur in the periphery may be repaired using a variety of operative procedures with high success rates. Complex multiplanar tears that extend into the central one-third avascular zone can also be successfully repaired using a meticulous vertically divergent suture technique. The outcome of these repairs justifies preservation of meniscal tissue, especially in younger athletic individuals. Meniscal transplantation is a valid treatment option for patients who have undergone meniscectomy and have related tibiofemoral joint pain, or in whom articular cartilage deterioration in the meniscectomized compartment is present. Rehabilitation after these operations includes knee motion and quadriceps-strengthening exercises initiated the first day postoperatively. The initial goal is to prevent excessive weight bearing and joint compressive forces that could disrupt the healing meniscus repair or transplant. The protocol contains modifications according to the type of meniscal tear, if a concomitant procedure is done (such as a ligament reconstruction) or if noteworthy articular cartilage deterioration is present. Patients who have repairs of peripheral meniscus tears are generally progressed more rapidly than those who have repairs of tears extending in the central one-third region or those who undergo meniscal transplantation. The safety and effectiveness of the rehabilitation program has been demonstrated in several clinical studies. We recommend preservation of meniscal tissue, regardless of age, in active patients whenever possible. J Orthop Sports Phys Ther 2006;36(10):795-814. doi:10.2519/jospt.2006.2177
\end{abstract}

Key Words: knee rehabilitation, meniscus repair, meniscus transplant

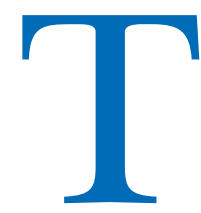

he meniscus provides important functions in the human knee, including load transmission across the knee joint, shock absorption, and joint nutrition, that are vital for the integrity of the articular cartilage. ${ }^{11,25,37}$ The menisci occupy $60 \%$ of the contact area between the tibial and femoral cartilage surfaces, and transmit $50 \%$ of joint compressive forces in full extension and approximately $85 \%$ of the load in $90^{\circ}$ of flexion. ${ }^{1}$ The menisci also contribute to knee joint stability and overall joint conformity, and have been suggested as a proprioceptive structure that

\footnotetext{
${ }^{1}$ Director of Rehabilitation, Cincinnati Sportsmedicine and Orthopaedic Center Rehabilitation, Cincinnati, $\mathrm{OH}$.

${ }^{2}$ Director of Clinical Studies, Cincinnati Sportsmedicine Research and Education Foundation, Cincinnati, $\mathrm{OH}$.

${ }^{3}$ Chairman and Medical Director, Cincinnati Sportsmedicine and Orthopaedic Center and Clinica Professor, Department of Orthopaedic Surgery, University of Cincinnati, Cincinnati, OH.

Address correspondence to: Sue Barber-Westin, c/o Cincinnati Sportsmedicine Research and Education
} Foundation, 10663 Montgomery Road, Cincinnati, OH 45242. E-mail: sbwestin@csmref.org provides a feedback mechanism for joint position sense. ${ }^{4}$ After total meniscectomy, the tibiofemoral contact area decreases by approximately $50 \%$, while contact forces increase 2- to 3-fold. ${ }^{1,26,46,47}$ Poor results have been reported following meniscectomy, with the development of arthrosis, a frequently reported consequence that includes flattening of the femoral condyle, development of osteophytes, and narrowing of the tibiofemoral joint space. ${ }^{23,42,44,45,74 \text {, }}$ 76,97

Over the past 2 decades, techniques to repair meniscus tears have been developed in an effort to preserve tissue and function. ${ }^{7,35,40,52,56,82,95}$ Most investigations have focused on suture repair of single longitudinal tears located in the outer one-third region, or periphery of the meniscus. Repairs of tears that extend 4 to $5 \mathrm{~mm}$ beyond the peripheral meniscal rim traditionally have been discouraged due to questions regarding healing potential and possibility of retears. However, preservation of meniscal tissue is an overwhelming rationale in young active patients and several authors have demonstrated that tears located in the central onethird avascular zone can be successfully repaired. $6,12,58,59,68,80,82,90$ A few reports have described re- 
sults of meniscal repair using fixators, such as arrows ${ }^{22,29,43,48,50,83,84}$ staples, ${ }^{49}$ and all-inside biodegradable screws ${ }^{32,38,69}$; however, arthroscopicassisted suture repair remains the gold standard and is our preferred method. In addition, we have demonstrated that a rehabilitation program that implements immediate knee motion the first postoperative day after meniscus repair (performed either alone or with anterior cruciate ligament [ACL] reconstruction) is not deleterious to the healing meniscus tissue and prevents knee arthrofibrosis. ${ }^{12,65,80}$

While many meniscus tears can be successfully repaired, not all are salvageable, especially if considerable tissue damage has occurred. Transplantation of human menisci was first reported in the English literature in $1984^{51}$ and, while results of clinical investigations are mixed, the procedure is hypothesized to restore some load-bearing meniscus function. . $8,53,54,61,63,72,73,79,85,88,89,93,96,98,99$ In young active patients who have undergone meniscectomy, few other options currently exist. The results of shortand mid-term clinical studies have justified the procedure in patients who have pain or in whom articular cartilage deterioration in the meniscectomized compartment exists. ${ }^{63,94}$

\section{EVALUATION}

A thorough history is taken, which includes assessment of prior operative records, current symptoms, and functional limitations. We developed and validated the Cincinnati Knee Rating System ${ }^{8}$ to document pain, swelling, and giving way of the knee as well as limitations with daily, athletic, and occupational activities. A comprehensive evaluation of the knee includes assessment of tibiofemoral joint pain on palpation and during joint motion, and palpable meniscus displacement during joint compression and distraction. A positive rotation and flexion test (McMurray test) is indicative of a possible meniscal tear. Patients with meniscal pathology typically present with tibiofemoral joint pain on palpation and during keep flexion activities. We also routinely evaluate the patellofemoral joint, all knee ligaments, and gait characteristics. ${ }^{66}$

Diagnostic imaging includes anteroposterior radiographs of both knees in full extension, a $45^{\circ}$ flexion lateral radiograph, and an axial view of the patellofemoral joint. The tibiofemoral joint space is assessed with $45^{\circ}$ weight-bearing posteroanterior radiographs. ${ }^{77}$ Axial alignment is measured using full-length, standing, hip-knee-ankle, weight-bearing radiographs $^{20}$ in knees that demonstrate varus or valgus alignment on physical examination. For the meniscus transplantation preoperative sizing assessment, plain anteroposterior and lateral radiographs are used to determine meniscus width and length. ${ }^{70}$ Spiral CT arthrography ${ }^{91}$ and magnetic resonance imaging (MRI) with proton density, fast-spin-echo techniques ${ }^{71,72}$ may be used to evaluate the status of the articular cartilage and subchondral bone to determine patient candidates for transplants.

\section{INDICATIONS AND CONTRAINDICATIONS}

Meniscal repair is indicated for patients under age 50 or those in their fifties who are athletically active. Tears in the peripheral one-third vascularized region ${ }^{5}$ are well suited for repair and have high success rates. Arnoczky and Warren ${ }^{5}$ previously described the vascularity of the menisci. The degrees of vascular penetration were $10 \%$ to $30 \%$ of the width of the medial meniscus and $10 \%$ to $25 \%$ of the width of the lateral meniscus. A vascular synovial covering was noted on the anterior and posterior horn attachments, and a synovial fringe was described on the femoral and tibial articular surfaces of both menisci.

While tears located in the central one-third region, which is less vascular, may be repaired, there must be $8 \mathrm{~mm}$ of intact meniscal tissue without fragmentation. Anatomic approximation and complete closure of all gaps at the tear site must be achieved to promote healing. Contraindications include tears located in the inner one-third region (rim width greater than 8 $\mathrm{mm})$, tears with major tissue fragmentation or degeneration, and tears with edges that cannot be reduced and approximated. Longitudinal tears less than 10 $\mathrm{mm}$ in length or incomplete radial tears that do not extend into the outer one-third of the meniscus are not repaired.

The indications for meniscus transplantation are prior total meniscectomy, age of 50 years or less, clinical symptoms of pain in the involved tibiofemoral compartment or articular cartilage degeneration, and $2 \mathrm{~mm}$ or more of tibiofemoral joint space on $45^{\circ}$ weight-bearing posteroanterior radiographs. ${ }^{77}$ The results of this operation are more favorable when it is done before the onset of advanced tibiofemoral joint arthrosis. ${ }^{61,63,72}$ Normal axial alignment and a stable joint are required, as untreated varus limb malalignment and ACL deficiency correlate with transplant failure. ${ }^{14,18,87,88}$

Contraindications for a meniscus transplant are advanced knee joint arthrosis, defined as less than 2 $\mathrm{mm}$ of tibiofemoral joint space on $45^{\circ}$ weight-bearing posteroanterior radiographs and MRI evidence of flattening of the femoral condyle, concavity of the tibial plateau, and osteophytes that prevent anatomic seating of the transplant. Knee joint instability is a contraindication unless the patient is willing to undergo ligament reconstruction either before or with the meniscus transplant. Other contraindications include knee arthrofibrosis, muscular atrophy, and prior joint infection. Axial malalignment of varus (weight-bearing line of less than $40 \%$ of the mediallateral transverse width of the tibial plateau) or valgus (weight-bearing line of greater than $60 \%$ ) is also a 
contraindication unless the patient is willing to undergo corrective osteotomy prior to the meniscus transplant procedure.

\section{SURGICAL TECHNIQUES}

\section{Meniscus Repair}

We have previously described in detail our insideout surgical technique for meniscus repair, ${ }^{52,80,81}$ which is similar to that originally described by Henning. ${ }^{35,36}$ All knees undergo an initial comprehensive arthroscopic examination. The $70^{\circ}$ arthroscope is used to examine posteromedial meniscal regions. The specific tear pattern, number of components of the tear, and remaining rim width are determined. Single tears occurring in 1 plane are classified as either longitudinal, radial, or horizontal. Tears with multiple components are classified as double-longitudinal, triple-longitudinal, flap, or complex multiplanar (Figures 1-5).

An accessory posteromedial or posterolateral incision is used for suture retrieval. A popliteal retractor (Stryker Co, Kalamazoo, MI) protects the posterior structures during suture passage. The meniscus repair site and synovial junction are rasped and loose meniscus fragments removed. Multiple 2-0 coated polyester nonabsorbable sutures (Ticron; Davis and Geck Co, Wayne, NJ; or Ethibond; Ethicon Inc, Sommerville, NJ) are placed every $4 \mathrm{~mm}$ along the length of the tear to achieve a meticulous reduction and stabilization at the repair site. A single-barrel straight or curved arthroscopic cannula (Richard Wolf Medical, Vernon Hills, IL) is used for suture passage.

The placement of sutures depends on the tear pattern. Single longitudinal tears are repaired with vertical divergent sutures, which are placed first in the superior (femoral) surface of the meniscus (Figure 1). These sutures reduce the meniscus to its anatomic attachment site and ensure that the supe-

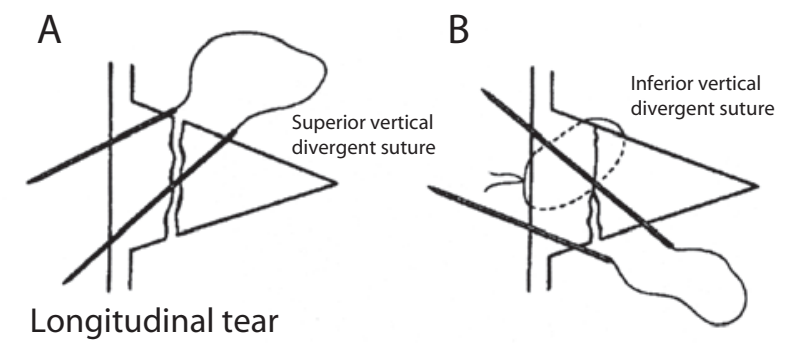

FIGURE 1. Double-stacked vertical suture pattern used in the repair of single longitudinal meniscal tears. (A) The superior sutures are placed first close to the superior gap and to anchor the meniscus to its bed. (B) The inferior sutures are then placed without displacing the tear. Reprinted with permission from McLaughlin J and Noyes FR: Arthroscopic meniscus repair: Recommended surgical techniques for complex meniscal tears. Tech Orthop 8: 129-136, 1993.
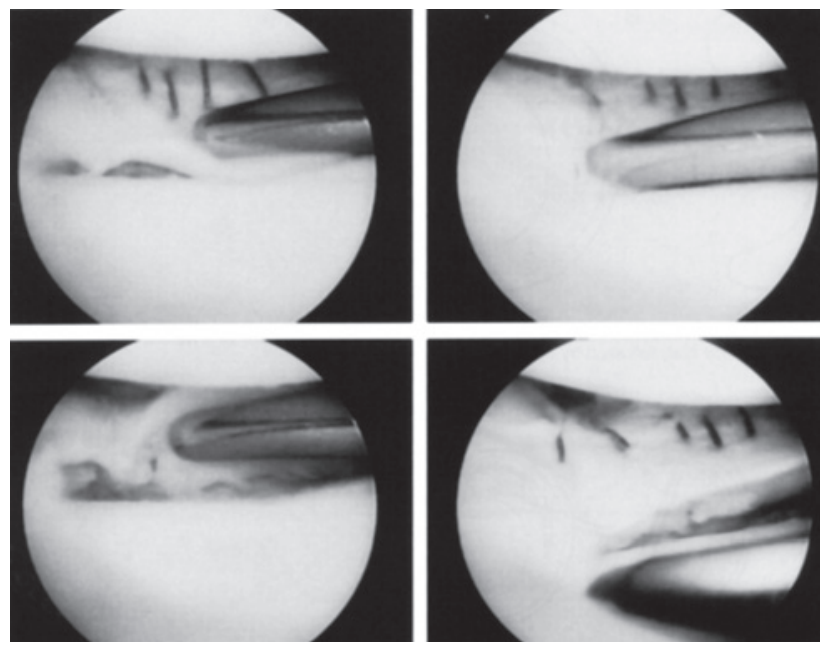

FIGURE 2. A longitudinal meniscal tear site demonstrating some fragmentation inferiorly (lower left). This tear required multiple superior and inferior vertical divergent sutures to achieve an anatomic reduction (upper right and left). Reprinted with permission from Noyes FR, Barber-Westin SD: Arthroscopic repair of meniscal tears extending into the avascular zone in patients younger than twenty years of age. Am J Sports Med 30: 589-600, 2002.
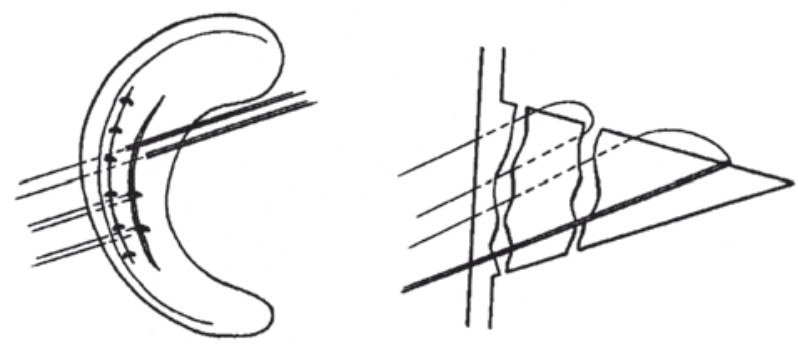

FIGURE 3. Suture technique for double longitudinal tears. The peripheral tear is repaired first with superior sutures, followed by repair of the inner tear in the same fashion. McLaughlin J and Noyes FR: Arthroscopic meniscus repair: Recommended surgical techniques for complex meniscal tears. Tech Orthop 8: 129-136, 1993.

rior surface does not displace when the cannula is later placed beneath the meniscus for the placement of inferior sutures on the tibial surface. The first pass of the suture is placed into the peripheral portion of the tear and the second pass is placed vertically through the central one-third region. The sutures are brought out through the posteromedial or posterolateral incision and tied directly over the meniscal attachment without any intervening tissues (Figure 2). The tension in each suture and meniscus tear reduction are confirmed by arthroscopic visualization after each suture is tied.

Double- and triple-longitudinal tears require additional sutures for each tear component (Figure 3). The peripheral tears are repaired first, followed by the tears in the central-third region. Vertical divergent sutures bridge both tear sites in the same fashion as described for single tears. Radial tears (Figure 4) and flap tears (Figure 5) are repaired with horizontal sutures placed perpendicular to the tear at 2- to 4-mm intervals. A micropick is used to penetrate 

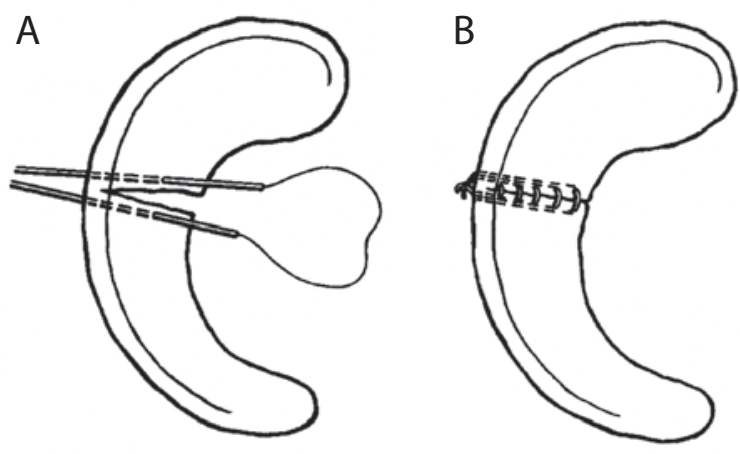

FIGURE 4. Repair technique for radial meniscal tears. The inner sutures (A) are placed first, followed by the peripheral sutures (B). McLaughlin J and Noyes FR: Arthroscopic meniscus repair: Recommended surgical techniques for complex meniscal tears. Tech Orthop 8: 129-136, 1993.
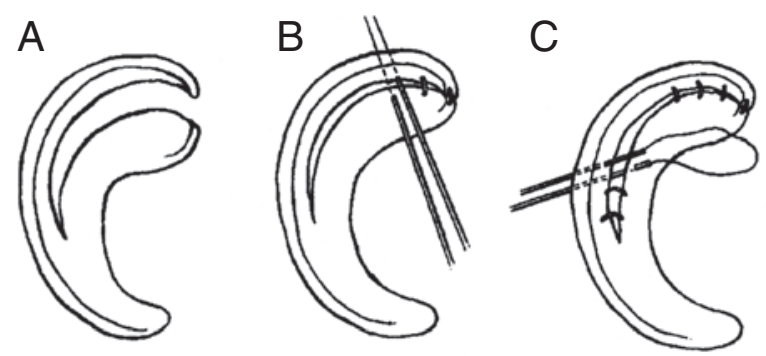

FIGURE 5. Repair technique for flap tears. (A) The tear is identified and reduced. (B) Horizontal tension sutures are placed to anchor the radial component of the tear. $(\mathrm{C})$ The longitudinal component is sutured using the double-stacked suture technique. McLaughlin J and Noyes FR: Arthroscopic meniscus repair: Recommended surgical techniques for complex meniscal tears. Tech Orthop 8: 129-136, 1993.

the femoral notch 3 to 4 times to introduce blood into the joint in an attempt to increase fibrin clot formation at the repair site.

\section{Lateral Meniscus Transplantation}

We have previously described the techniques for medial and lateral meniscus transplantation in detail. ${ }^{63,64}$ Our preferred method is a central bone bridge technique, which maintains a bridge of bone between the anterior and posterior meniscal attachments. The meniscus bed is first prepared by removing any residual meniscus tissue (leaving a 2- to 3-mm meniscus rim) and rasping the adjacent synovium. Lateral meniscus transplants contain a rectangular portion of bone from the tibial plateau, which incorporates the anterior and posterior attachments, and measures 8 to $9 \mathrm{~mm}$ in width and $10 \mathrm{~mm}$ in depth. The length of the bone attachment is usually $35 \mathrm{~mm}$, but can be modified if necessary.

The patient is placed in a supine position on the operating room table with a tourniquet applied with a leg holder and the table adjusted to allow $90^{\circ}$ of knee flexion. Examination of the knee is conducted under anesthesia, followed by diagnostic arthroscopy to confirm the preoperative diagnosis and determine the condition of the articular cartilage. One 3-cm lateral arthrotomy is made just adjacent to the patellar tendon and a second 3-cm posterolateral accessory incision is created just behind the lateral collateral ligament. ${ }^{52,81}$ The lateral head of the gastrocnemius is gently dissected with Metzenbaum scissors off the posterior capsule at the joint line, followed by further dissection bluntly. A popliteal retractor (Stryker Co, Kalamazoo, MI) is placed directly behind the lateral meniscus bed. The tourniquet is inflated only for these 2 approaches; otherwise, it is not used.

The dimensions of the transplant are measured. A template is made out of aluminum foil of the transplant width and length and is placed into the lateral compartment to determine the lateralmost margin of the bone trough. A rectangular bone trough is prepared at the anterior and posterior tibia attachment sites to match the dimensions of the prepared lateral meniscus transplant.

The anterior and posterior horns of the transplant are placed into their normal attachment locations, just adjacent to the ACL. The transplant is inserted into the trough with its bone portion seated against the posterior bone buttress to achieve correct anterior-to-posterior placement of the attachment sites (Figure 6A). A vertical suture in the posterior meniscus body is passed posteriorly to provide tension and facilitate placement of the transplant. The knee is flexed, extended, and rotated to confirm correct placement has been achieved. The posterior suture is tied and additional sutures are placed in a vertical fashion into the anterior one third of the meniscus, attaching it to the rim under direct visualization. Fixation is achieved with an absorbable interference screw, which is placed medial and adjacent to the central bone attachment. ${ }^{24}$ The arthrotomy is closed and an inside-out meniscal repair is performed with multiple vertical divergent sutures, which are placed first superiorly to reduce the meniscus, and then inferiorly in the outer one-third of the transplant (Figure 6B).

In knees that require a concomitant ACL reconstruction, an arthroscopically assisted approach is used as described previously. ${ }^{60}$ The femoral and tibial tunnels are drilled and the ACL graft is passed through the tunnels with femoral fixation done first, followed by the meniscal transplantation, and then tibial cruciate graft fixation. Accomplishing ACL graft fixation at the tibia as the final step allows for maximum separation of the tibiofemoral joint to be obtained during the meniscal transplantation procedure. This also prevents potential failure or problems with the ACL graft and fixation during the operation. 

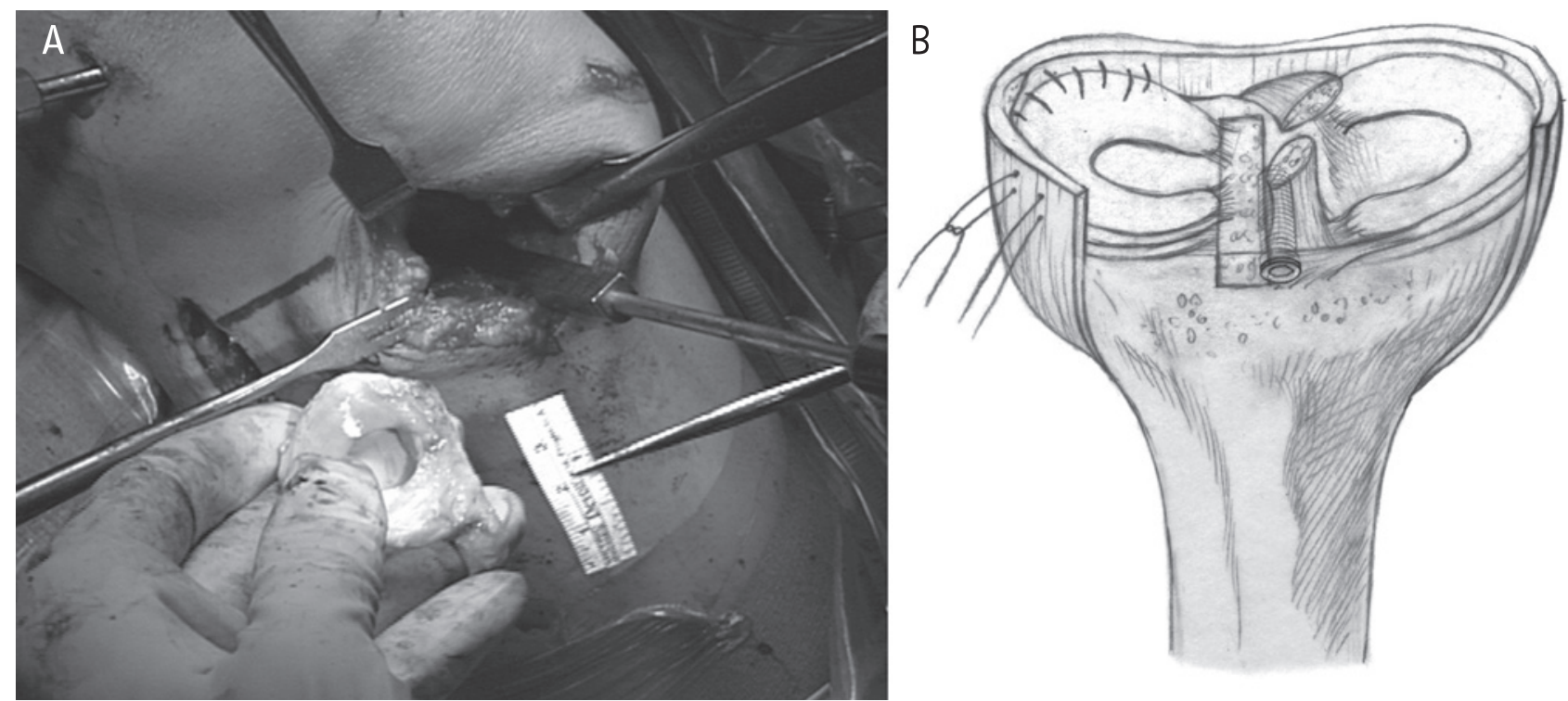

FIGURE 6. (A) Lateral meniscus transplant is ready to be placed into the tibial slot using the central bone bridge technique. (B) Lateral meniscus transplant in place and sutured. Reprinted with permission, Noyes FR, Barber-Westin SD, Rankin M: Meniscal transplantation in symptomatic patients less than fifty years old: Surgical technique. J Bone Joint Surg Sep 2005;87 Suppl 1(Pt 2):149-165.

\section{Medial Meniscus Transplantation}

There are 2 techniques for medial meniscus transplantation: the central bone bridge technique, which is preferred, and a 2-tunnel technique that consists of separate anterior and posterior bone attachments and tunnels. ${ }^{64}$ The decision-making criteria for the appropriate technique is made following exposure and direct measurement of the anterior-posterior and medial-lateral dimensions required for the transplant. The central bone bridge technique is used if the surgeon determines that the transplant will fit in the proper position just adjacent to the ACL tibial attachment, without excessive medial tibial overhang, and that the anterior and posterior attachment locations will be anatomically correct. If the transplant requires adjustment to fit to the medial tibial plateau (by moving the anterior horn placement further laterally), then the 2-tunnel technique is selected.

The central bone bridge technique is the same as described for lateral meniscus transplants. The tibial slot is prepared to the dimensions of 8 to $9 \mathrm{~mm}$ in width and $10 \mathrm{~mm}$ in depth. The central bone bridge of the transplant is sized to a width of $7 \mathrm{~mm}$ (or 1 $\mathrm{mm}$ less than the dimension at the tibial site) and a depth of $10 \mathrm{~mm} .{ }^{24}$ A vertical suture is placed through the junction of the posterior and middle thirds of the transplant. The meniscus is passed through an arthrotomy into the knee, with tension applied on the sutures to facilitate proper positioning (Figure $7 \mathrm{~A})$. The bone bridge of the transplant is aligned with the recipient tibial slot and the knee is flexed, extended, and rotated to confirm proper alignment. An absorbable bone interference screw is inserted adjacent to the bone bridge (Figure 7B). The meniscus transplant is sutured with vertical divergent su- tures (2-0 Ethibond) under direct visualization. The anterior arthrotomy is closed and inside-out vertical divergent sutures are placed to suture the meniscus to the bed, remove any implant undulations, and restore circumferential meniscal tension.

If it is determined that the central bone bridge technique cannot be performed, the surgeon must use the 2-tunnel technique. The medial meniscus transplant is fashioned to create a posterior bone plug $8 \mathrm{~mm}$ in diameter and $12 \mathrm{~mm}$ in length, and an anterior bone plug $12 \mathrm{~mm}$ in diameter and $12 \mathrm{~mm}$ in length. Two 2-0 nonabsorbable Ethibond sutures are passed retrograde through each bone plug. Two other sutures are placed in the meniscus adjacent to the bone attachment for subsequent secure fixation of the bone plugs within the tibial tunnel. A tibial tunnel is created at the anatomic posterior horn meniscus attachment, just medial and proximal to the posterior cruciate ligament (PCL) attachment.

A 3-cm anteromedial arthrotomy is created, through which the posterior bone portion of the transplant will be passed. Secondary meniscus body sutures are passed out the posteromedial approach. The knee is flexed to $20^{\circ}$ under a maximum valgus load to pass the posterior bone portions of the transplant; the secondary meniscus body suture is held by an assistant. Care is taken not to advance the posterior meniscus body into the tibial tunnel, but to just seat the bone portion of the graft in order not to shorten the meniscus transplant. The posterior meniscus bone attachment and midbody sutures are tied over a tibial post to provide tension in the posterior bone attachment and posterior one third of the meniscus. The knee is flexed, extended, and rotated to assess whether the transplant is in the correct position in the joint. 

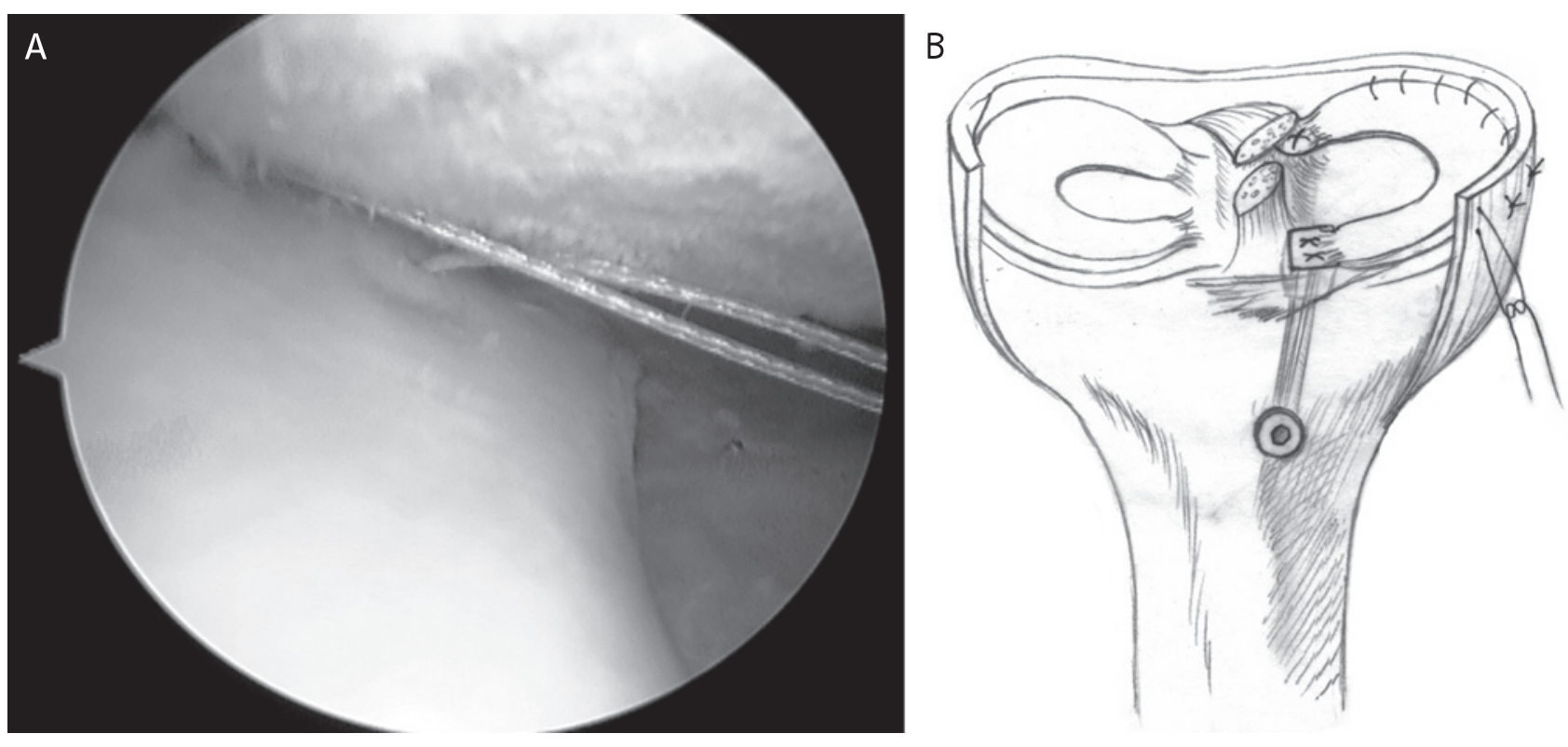

FIGURE 7. (A) Arthroscopic appearance of medial meniscus transplant. (B) Medial meniscus transplant with fixation of anterior and posterior bone attachments into separate tibial tunnels. Reprinted with permission, Noyes FR, Barber-Westin SD, Rankin M: Meniscal transplantation in symptomatic patients less than fifty years old: Surgical technique. J Bone Joint Surg Sep 2005;87 Suppl 1(Pt 2):149-165.

A 12-mm rectangular bone attachment is fashioned to correspond to the anterior bone portion of the meniscus transplant. A 4-mm bone tunnel is created at the base of this bone trough, which exits at the anterior tibia, and through which the anterior horn is seated. Full knee flexion, extension, and rotation are performed to determine proper transplant placement and fit. Starting in the posterior horn, an inside-out meniscus repair is performed using multiple vertical divergent sutures both superiorly and inferiorly. Constant tension is placed on the transplant (from posterior to anterior) to restore circumferential tension (Figure 8).

\section{POSTOPERATIVE REHABILITATION}

\section{Clinical Concepts}

The postoperative rehabilitation program for meniscus repair and transplantation is summarized in Table 1. The initial goal of the program is to prevent excessive weight-bearing forces. This limitation is designed to control high compressive and shear forces that could disrupt the healing meniscus repair or transplant. There are variations in the protocol according to the type, location, and size of the meniscus tear. Peripheral repairs heal rapidly, whereas complex repairs extending into the central avascular region heal more slowly and require greater caution. Radial repairs must be especially protected, as excessive weight bearing early postoperatively can disrupt the repair site. In addition, modifications may be required if a concomitant procedure is done (such as a ligament reconstruction), or if noteworthy articu-

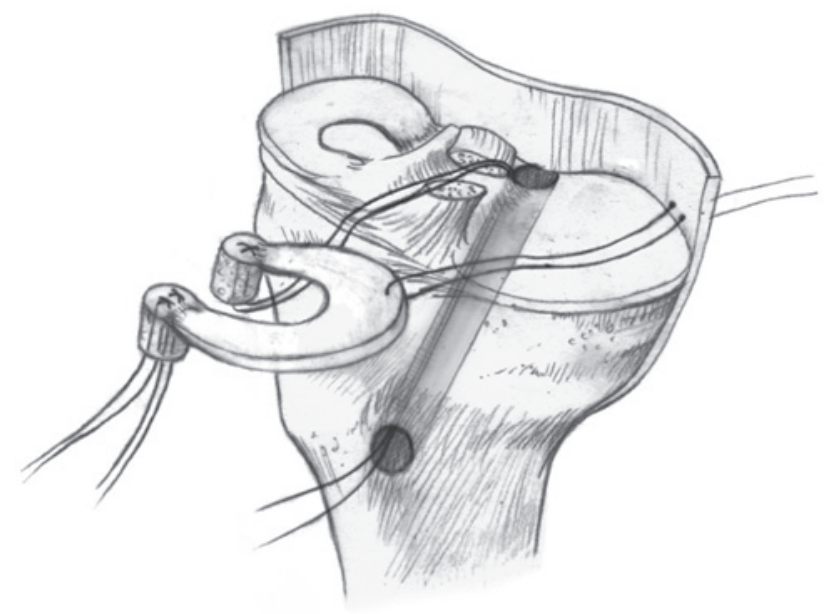

FIGURE 8. Two-tunnel technique for a medial meniscus transplant The illustration shows insertion of transplant, including posteromedial suture placed to facilitate meniscus reduction. The anterior and posterior bone attachments of the medial meniscus transplant are fixed into separate tibial tunnels. Reprinted with permission, Noyes FR, Barber-Westin SD, Rankin M: Meniscal transplantation in symptomatic patients less than fifty years old: Surgical technique. J Bone Joint Surg Sep 2005;87 Suppl 1(Pt 2):149-165.

lar cartilage deterioration is present. This program has been used at our Center in over 170 meniscus transplants and over 500 meniscus repairs, and the results of our clinical investigations ${ }^{58,59,63,80}$ demonstrate its safety and effectiveness in restoring normal knee motion, muscle, and gait characteristics. 
TABLE 1. Rehabilitation protocol summary for meniscus repairs and transplants.

\begin{tabular}{|c|c|c|c|c|c|c|c|c|c|}
\hline & \multicolumn{5}{|c|}{ Postoperative Weeks } & \multicolumn{4}{|c|}{ Postoperative Months } \\
\hline & $1-2$ & $3-4$ & $5-6$ & $7-8$ & $9-12$ & 4 & 5 & 6 & $7-12$ \\
\hline Brace: long-leg postoperative & C,T & $\mathrm{C}, \mathrm{T}$ & $\mathrm{C}, \mathrm{T}$ & & & & & & \\
\hline \multicolumn{10}{|l|}{ Range of motion minimum goals } \\
\hline $0^{\circ}-90^{\circ}$ & $x$ & & & & & & & & \\
\hline $0^{\circ}-120^{\circ}$ & & $x$ & & & & & & & \\
\hline $0^{\circ}-135^{\circ}$ & & & $\mathrm{x}$ & & & & & & \\
\hline \multicolumn{10}{|l|}{ Weight bearing } \\
\hline Toe touch to $1 / 2$ body weight & $\mathrm{P}$ & & & & & & & & \\
\hline $3 / 4$ to full body weight & & $P$ & & & & & & & \\
\hline Toe touch to $1 / 4$ body weight & $\mathrm{C}, \mathrm{T}$ & & & & & & & & \\
\hline $1 / 2-3 / 4$ body weight & & $\mathrm{C}, \mathrm{T}$ & $\mathrm{C}$ & & & & & & \\
\hline Full body weight & & & $\mathrm{T}$ & $\mathrm{C}$ & & & & & \\
\hline Patellar mobilization & $x$ & $\mathrm{x}$ & $\mathrm{x}$ & & & & & & \\
\hline \multicolumn{10}{|l|}{ Stretching } \\
\hline $\begin{array}{l}\text { Hamstring, gastrocnemius, soleus, iliotibial } \\
\text { band, quadriceps }\end{array}$ & $x$ & $x$ & $x$ & $x$ & $x$ & $X$ & $X$ & $x$ & $X$ \\
\hline \multicolumn{10}{|l|}{ Strengthening } \\
\hline $\begin{array}{l}\text { Quad isometrics, straight leg raises, active } \\
\text { knee extension }\end{array}$ & $x$ & $x$ & $x$ & $x$ & $x$ & $x$ & $X$ & $x$ & $X$ \\
\hline $\begin{array}{l}\text { Weight bearing: gait retraining, toe raises, } \\
\text { wall sits, mini-squats }\end{array}$ & & $P$ & $\mathrm{C}$ & $x$ & $x$ & $x$ & $X$ & $x$ & \\
\hline Knee flexion hamstring curls $\left(90^{\circ}\right)$ & & & $\mathrm{P}$ & $\mathrm{C}$ & $X$ & $X$ & $X$ & $\mathrm{x}$ & $X$ \\
\hline Knee extension quads $\left(90^{\circ}-30^{\circ}\right)$ & & & $\mathrm{x}$ & $\mathrm{X}$ & $x$ & $\mathrm{x}$ & $\mathrm{X}$ & $\mathrm{x}$ & $x$ \\
\hline Hip abduction-adduction, multihip & & & $\mathrm{x}$ & $x$ & $\mathrm{X}$ & $\mathrm{x}$ & $\mathrm{x}$ & $\mathrm{x}$ & $x$ \\
\hline Leg press $\left(70^{\circ}-10^{\circ}\right)$ & & & $P$ & $P$ & $\mathrm{x}$ & $x$ & $x$ & $x$ & $\mathrm{x}$ \\
\hline \multicolumn{10}{|l|}{ Balance/proprioceptive training } \\
\hline $\begin{array}{l}\text { Weight-shifting, mini-trampoline, BAPS, } \\
\text { KAT, plyometrics }\end{array}$ & & $P$ & $x$ & $x$ & $x$ & $x$ & $x$ & $x$ & $X$ \\
\hline \multicolumn{10}{|l|}{ Conditioning } \\
\hline UBE & & $\mathrm{x}$ & $x$ & $\mathrm{x}$ & & & & & \\
\hline Bike (stationary) & & & & $x$ & $X$ & $x$ & $\mathrm{x}$ & $\mathrm{x}$ & $x$ \\
\hline Aquatic program & & & & & $X$ & $\mathrm{x}$ & $\mathrm{x}$ & $x$ & $\mathrm{x}$ \\
\hline Swimming (kicking) & & & & & $P, C$ & $\mathrm{x}$ & $x$ & $\mathrm{x}$ & $\mathrm{x}$ \\
\hline Walking & & & & & $x$ & $x$ & $x$ & $x$ & $x$ \\
\hline Stair-climbing machine & & & & & $\mathrm{P}, \mathrm{C}$ & $\mathrm{P}, \mathrm{C}$ & $\mathrm{P}, \mathrm{C}$ & $\mathrm{P}, \mathrm{C}$ & $\mathrm{x}$ \\
\hline Ski machine & & & & & $\mathrm{P}, \mathrm{C}$ & $\mathrm{P}$ & $P$ & $\mathrm{C}$ & $x$ \\
\hline Running: straight* & & & & & & $P$ & $P$ & C & $x$ \\
\hline Cutting: lateral carioca, figure $8 \mathrm{~s}^{*}$ & & & & & & & $\mathrm{P}$ & $\mathrm{P}$ & $x$ \\
\hline Full sports* & & & & & & & $\mathrm{P}$ & $\mathrm{P}$ & $x$ \\
\hline
\end{tabular}

Abbreviations: BAPS, Biomechanical Ankle Platform System (Camp, Jackson, Ml); C, complex meniscus repairs extending into central one-third region; KAT, Kinesthetic Awareness Trainer (Breg, Inc, Vista, CA); P, peripheral meniscus repairs; T, transplants; UBE, upper body ergometer; $X$, all meniscus repairs and transplants.

*Return to running, cutting, and full sports, based on multiple criteria (see text). Patients with noteworthy articular cartilage damage are advised to return to light recreational activities only.

The supervised physical therapy program is supplemented with home exercises performed on a daily basis. The therapist must evaluate the patient thoroughly to implement the appropriate protocol, and should examine the patient in the clinic and use therapeutic procedures and modality treatments required for successful rehabilitation. For the majority of patients, 11 to 16 postoperative physical therapy visits are expected over the course of 9 to 12 months to produce a desirable result. Important postoperative signs the therapist must monitor include swelling of the knee joint or soft tissues, pain, gait pattern, knee flexion and extension, patellar mobility, strength and control of the lower extremity, lower extremity flex- ibility, and tibiofemoral symptoms indicative of a meniscal tear (Table 2).

Patients are warned that an early return to strenuous activities, including impact loading, jogging, deep knee flexion, or pivoting, carries a definite risk of a repeat meniscus tear or tear to the transplant. This is particularly true in the first 4 to 6 months postoperatively, where full flexion or deep-squatting activities may disrupt the healing repair sites or transplants. Plain radiographs (lateral and anterior-posterior) are obtained at 1 week postoperatively to verify the position of the osseous component of meniscus transplants, and at 6 to 8 weeks postoperatively to verify healing and retention of the bony portion of 
TABLE 2. Postoperative signs and symptoms requiring prompt treatment.

\begin{tabular}{|c|c|}
\hline $\begin{array}{l}\text { Postoperative Sign, } \\
\text { Symptom }\end{array}$ & $\begin{array}{c}\text { Treatment } \\
\text { Recommendations }\end{array}$ \\
\hline $\begin{array}{l}\text { Continued pain in the medial } \\
\text { or lateral tibiofemoral com- } \\
\text { partment of the meniscus re- } \\
\text { pair or transplant }\end{array}$ & $\begin{array}{l}\text { Physician examination, assess } \\
\text { need for refixation or rerepair }\end{array}$ \\
\hline $\begin{array}{l}\text { Tibiofemoral compartment } \\
\text { clicking, or a subjective sen- } \\
\text { sation by the patient of } \\
\text { "something being loose" } \\
\text { within the tibiofemoral joint }\end{array}$ & $\begin{array}{l}\text { Physician examination, assess } \\
\text { need for refixation or rerepair }\end{array}$ \\
\hline $\begin{array}{l}\text { Failure to meet knee extension } \\
\text { and flexion goals (see text) }\end{array}$ & $\begin{array}{l}\text { Overpressure program, early } \\
\text { gentle manipulation under } \\
\text { anesthesia if } 0^{\circ}-135^{\circ} \text { not met } \\
\text { by } 6 \text { wk postoperatively }\end{array}$ \\
\hline $\begin{array}{l}\text { Decreased patellar mobility } \\
\text { (indicative of early } \\
\text { arthrofibrosis) }\end{array}$ & $\begin{array}{l}\text { Aggressive knee flexion, exten- } \\
\text { sion overpressure program, or } \\
\text { gentle manipulation under } \\
\text { anesthesia to regain full } \\
\text { ROM and normal patellar } \\
\text { mobility }\end{array}$ \\
\hline $\begin{array}{l}\text { Decrease in voluntary } \\
\text { quadriceps contraction and } \\
\text { muscle tone, advancing } \\
\text { muscle atrophy }\end{array}$ & $\begin{array}{r}\text { Aggressive quadriceps muscle } \\
\text { strengthening program, EMS }\end{array}$ \\
\hline $\begin{array}{l}\text { Persistent joint effusion, joint } \\
\text { inflammation }\end{array}$ & $\begin{array}{l}\text { Aspiration, rule out infection, } \\
\text { close physician observation }\end{array}$ \\
\hline
\end{tabular}

Abbreviation: EMS, electrical muscle stimulation; ROM, range of knee motion.

the transplant within the slot or tunnels. Any onset of joint line clicking or pain may indicate failure of the meniscus repair or transplant, and should be reported to the surgeon immediately for consideration of refixation.

\section{Immediate Postoperative Management}

In our Center, patients are educated before surgery on specific instructions regarding the postoperative rehabilitation protocol so they have a thorough understanding of what is expected after surgery. The first day postoperatively, patients present to physical therapy after discharge from the hospital on bilateral axillary crutches in a postoperative dressing in a long-leg brace locked in full extension. The postoperative bandage and dressing are changed to allow the application of thigh-high compression stockings and a compression bandage. Early control of postoperative effusion is essential for pain management and early quadriceps re-education. In addition to the compression program, cryotherapy is critical and our patients receive a commercial cooling unit (ICEMAN; djortho, San Diego, CA) which is used 6 to 8 times daily at home. This unit is placed on the patient as a part of the postoperative bandage. Clinically, devices, such as the Game Ready (Game Ready, Berkley, CA) cryotherapy machine, are used to provide compression with the cold program (Figure 9).

The patient is instructed to maintain elevation of the lower limb as often as possible during the first week after surgery. Patients are also fit and instructed in the use of a portable neuromuscular electric stimulator such as the EMPI PV 300 (EMPI, St Paul, $\mathrm{MN}$ ), which we have found to be effective for quadriceps re-education and pain management (Figure 10). Patients are instructed to use the device for 15-minute sessions, 6 times per day. This device is used until the patient displays an excellent voluntary quadriceps contraction.

The initial 2-week-postoperative period sets the tone for the early program progression. Due to the location of the repair incision and the extensive nature of the repair or transplant, symptoms such as pain, swelling, quadriceps shutdown, range of motion (ROM) limitations, and saphenous nerve irritation are common postoperative complications. The clinician should monitor patient complaints or symptoms of posteromedial or infrapatellar burning sensations, posteromedial tenderness along the distal pes anserine tendons, tenderness of Hunter's canal along the medial thigh, hypersensitivity to light pressure, or hypersensitivity to temperature change. Early recognition and treatment of these problems is critical for a successful outcome.

\section{Brace and Crutch Support}

Immediately postoperatively, patients who had repairs of complex meniscus tears or transplants are placed in a long-leg postoperative brace, which is worn for 6 weeks. The brace is opened from $0^{\circ}$ to $90^{\circ}$ immediately postoperatively, but is locked at $0^{\circ}$ extension at night for the first 2 weeks. Thereafter, the brace is not routinely locked except in patients who

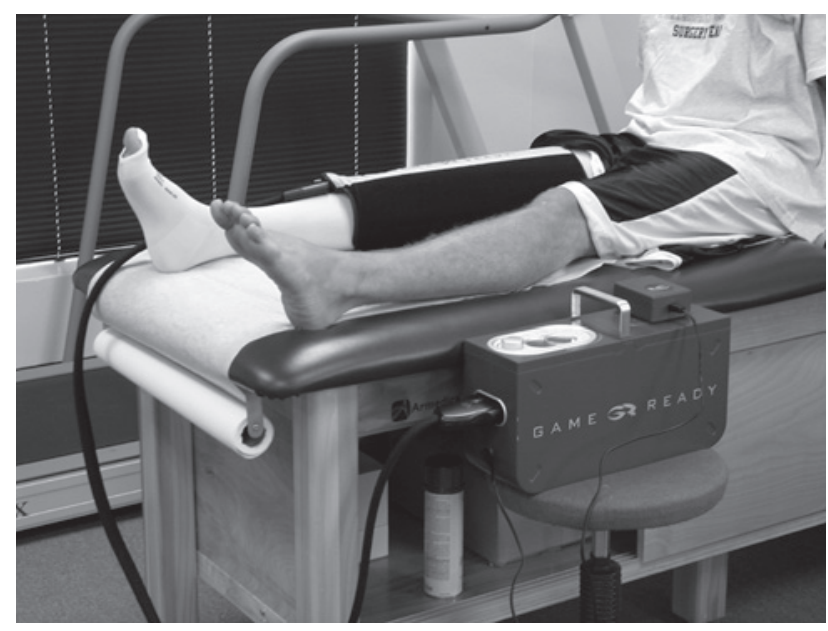

FIGURE 9. A clinical cryotherapy machine that provides compression with the cold program (Game Ready, Berkley, CA) is used in the initial postoperative period. 


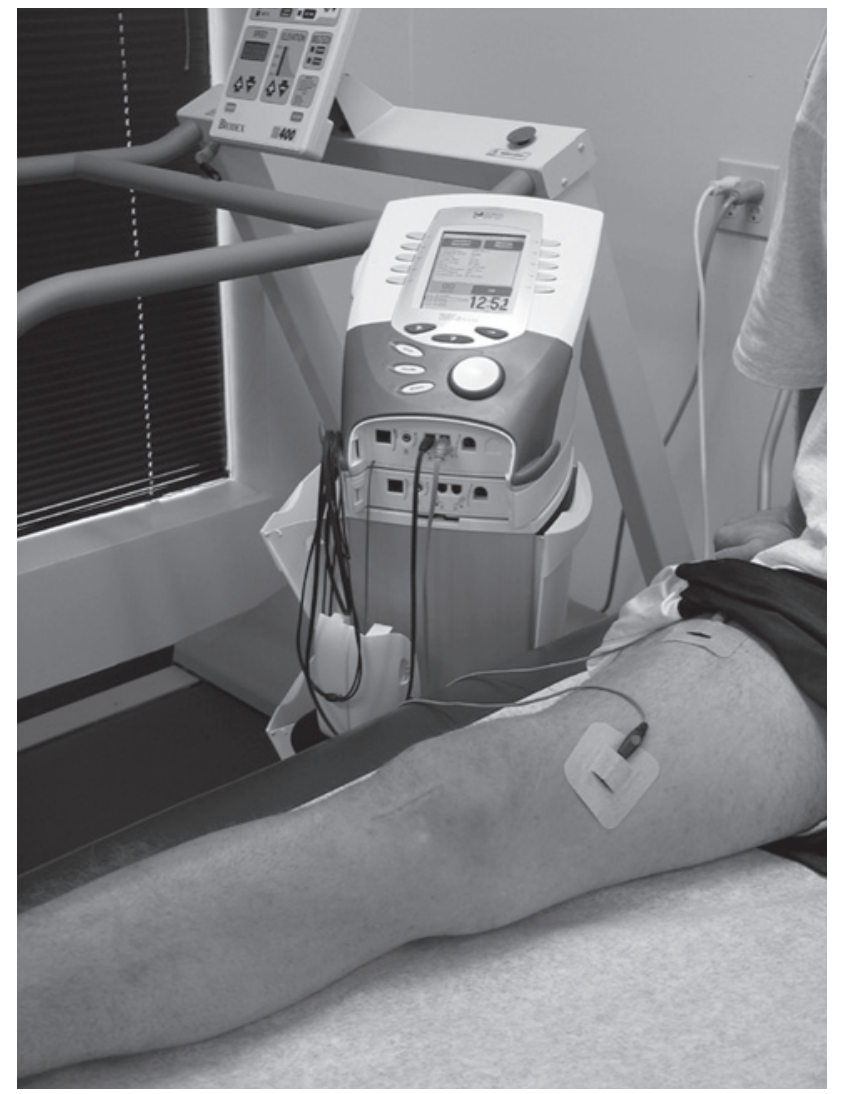

FIGURE 10. A portable neuromuscular electric stimulator (EMPI, St Paul, MN) is effective for quadriceps re-education and pain management in the early postoperative phase.

cannot maintain $0^{\circ}$ of extension. In these cases, the brace is locked at $0^{\circ}$ extension as required during the day and night. A brace is not routinely used after repair of a peripheral meniscus tear.

Crutches with partial weight bearing are used for the first 4 weeks to protect the repair site in all cases. Weight bearing is gradually progressed as shown in Table 1, and patients are encouraged to use a normal gait technique that avoids a locked-knee position and encourages normal knee flexion throughout the gait cycle.

\section{Range of Knee Motion and Flexibility}

We instruct the patient to perform passive knee flexion and passive and active/active-assisted knee extension exercises beginning the first day postoperatively. Active knee flexion is limited to avoid hamstring strain to the posteromedial joint. Initially, these exercises are performed in the seated position from $0^{\circ}$ to $90^{\circ}$, with flexion advanced to $120^{\circ}$ by the third to fourth week, and $135^{\circ}$ by the fifth to sixth week (Table 3). ROM exercises are performed 3 to 4 times daily (10- to 15-minute sessions) until normal motion is achieved. Full extension is considered to be $0^{\circ}$. Caution is used to avoid hyperextension in individuals who have had anterior-horn meniscus repairs.

A knee with an extensive repair may be required to limit $\mathrm{ROM}$ to $0^{\circ}$ to $90^{\circ}$ for the first 2 weeks before progressing the ROM program. If $90^{\circ}$ is not easily achieved, the patient may be at risk for a flexion complication. Individuals who develop a limitation in either flexion or extension are placed into a specific treatment program early postoperatively, as previously described in detail. ${ }^{34,65}$ An overpressure program is usually successful in achieving the last few degrees of extension, if initiated within the first few weeks postoperative. The patient is instructed to prop the foot and ankle on a towel to elevate the hamstrings and gastrocnemius, which allows the knee to drop into full extension. A 4.5-kg (10-lb) weight may be added to the distal thigh and knee to provide overpressure to stretch the posterior capsule. This program is done 6 to 8 times per day, for 10 minutes at a time. Flexion exercises are done in the seated position, using the opposite lower extremity to provide overpressure. Other options include chair rolling, wall sliding, passive quadriceps stretching, and ROM devices such as the ERMI Knee Flexionator (ERMI, Atlanta, GA).

ROM exercises are accompanied by patellar mobilization (in the superior, inferior, medial, and lateral directions), which we believe is paramount to promote full knee ROM (Figure 11). Flexibility exercises, beginning with the hamstring and gastrocsoleus musculatures, are also initiated the day following surgery and are done 3 times per day. Quadriceps and iliotibial band flexibility exercises are incorporated at 7 to 8 weeks postoperative. Sustained static stretching is performed, with the stretch held for 30 seconds and repeated 5 times.

Our ROM program has been proven throughout many years to be effective, as no patient who has undergone an isolated meniscus repair or transplant has required further arthroscopic surgery or lysis of adhesions for a knee motion complication. In our studies, only 2 of 193 patients who underwent meniscal repair, and 4 of 38 patients who had a transplant, required a gentle manipulation for a limitation of flexion. In these 6 patients, a major concomitant procedure, such as an ACL or PCL reconstruction, had been performed. The therapist should be aware of the increased potential of a knee motion problem in patients who undergo combined procedures, and that closer supervision and additional exercises may be required to successfully restore normal ROM. We have not experienced a difference between medial and lateral meniscus repairs or transplants in regard to knee motion complications.

\section{Balance and Proprioceptive Training}

Balance and proprioception exercises are initiated when patients achieve partial weight bearing. Crutches are used for support during these exercises until full weight bearing is achieved. Initially, patients perform weight shifting from side-to-side and front-toback. Then, cup walking is encouraged to develop 
TABLE 3. Range of motion, flexibility, and modality usage following meniscus repair and transplantation.

\begin{tabular}{|c|c|c|c|c|c|}
\hline Time Postoperative/Frequency & $\begin{array}{l}\text { Extension- } \\
\text { Flexion Limits }\end{array}$ & $\begin{array}{c}\text { Patellar } \\
\text { Mobilization }\end{array}$ & $\begin{array}{l}\text { Flexibility, } \\
5 \text { reps, } 20 \text { s }\end{array}$ & $\begin{array}{l}\text { Electrical Muscle } \\
\text { Stimulation, } \\
20 \text { min }\end{array}$ & $\begin{array}{c}\text { Cryotherapy } \\
20 \mathrm{~min}\end{array}$ \\
\hline \multicolumn{6}{|l|}{$1-2 \mathrm{wk}$} \\
\hline 3-4 times per d, 10-min sessions & $0^{\circ}-90^{\circ}$ & $\begin{array}{l}\text { Medial-lateral, } \\
\text { superior-inferior }\end{array}$ & $\begin{array}{l}\text { Hamstring, } \\
\text { gastrocsoleus }\end{array}$ & Yes & Yes \\
\hline \multicolumn{6}{|l|}{$3-4 \mathrm{wk}$} \\
\hline 3-4 times per d, 10-min sessions & $0^{\circ}-120^{\circ}$ & $\begin{array}{l}\text { Medial-lateral, } \\
\text { superior-inferior }\end{array}$ & $\begin{array}{l}\text { Hamstring, } \\
\text { gastrocsoleus }\end{array}$ & Yes & Yes \\
\hline \multicolumn{6}{|l|}{$5-6 w k$} \\
\hline 3 times per $\mathrm{d}, 10-\mathrm{min}$ sessions & $0^{\circ}-135^{\circ}$ & $\begin{array}{l}\text { Medial-lateral, } \\
\text { superior-inferior }\end{array}$ & $\begin{array}{l}\text { Hamstring, } \\
\text { gastrocsoleus }\end{array}$ & Yes & Yes \\
\hline \multicolumn{6}{|c|}{ 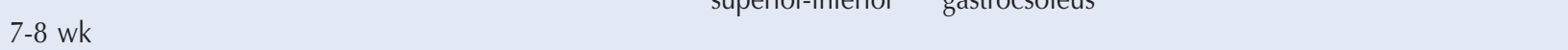 } \\
\hline 2 times per $\mathrm{d}, 10$-min sessions & $0^{\circ}-135^{\circ}$ & (if required) & $\begin{array}{l}\text { Hamstring, } \\
\text { gastrocsoleus, } \\
\text { quadriceps, } \\
\text { iliotibial band }\end{array}$ & & Yes \\
\hline \multicolumn{6}{|l|}{$9-52$ wk } \\
\hline 2 times per d, 10-min sessions & (should be full) & & $\begin{array}{l}\text { Hamstring, } \\
\text { gastrocsoleus, } \\
\text { quadriceps, } \\
\text { iliotibial band }\end{array}$ & & Yes \\
\hline
\end{tabular}

symmetry between the surgical and contralateral limbs, hip and knee flexion, quadriceps control during midstance, hip and pelvic control during midstance, and adequate gastrocsoleus control during push-off (Figure 12). Tandem balance can be initiated during the partial weight-bearing phase to assist with position sense and balance. The single-leg balance exercise is also beneficial and is done by pointing the foot straight ahead, flexing the knee to $20^{\circ}$ to $30^{\circ}$, extending the arms outward to horizontal, and positioning the torso upright with the shoulders above the hips and the hips above the ankles. The objective is to stand in position until balance is disturbed. A mini-trampoline makes this exercise more challenging after it is mastered on a hard surface.

A variety of devices are available to assist with balance and gait retraining, including lower-end devices consisting of Styrofoam half rolls, whole rolls, and the Biomechanical Ankle Platform System (BAPS, Camp, Jackson, MI). Patients walk (unassisted) on Styrofoam half rolls to develop balance, quadriceps control in midstance, and postural positioning. The BAPS board is used in double-leg and single-leg stance to promote proprioception. More sophisticated devices are also available (Figure 13), including Biodex's Stabilometry System (Biodex Corporation, Shirley, NY) and Neurocom's Balance System (Neurocom, Clackamas, OR). These devices provide visual feedback to assist with a variety of balance activities.

In the later phase of rehabilitation, plyometric exercises are incorporated to provide a functional

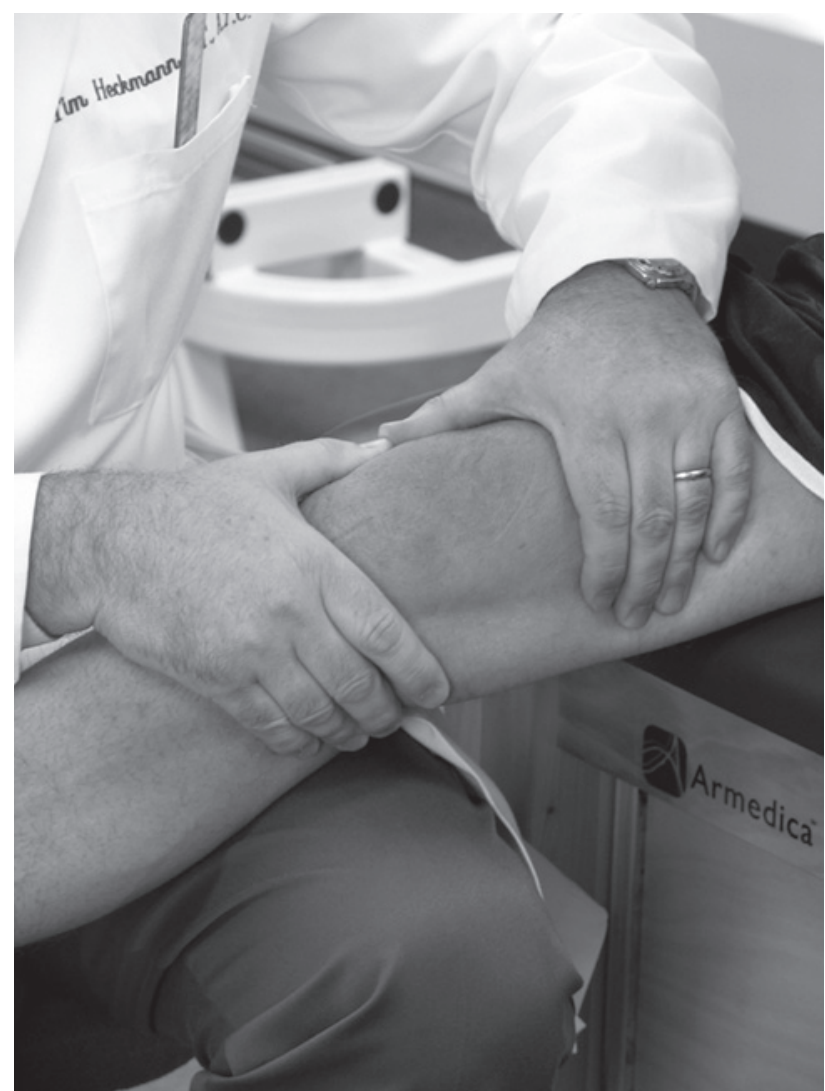

FIGURE 11. Patellar mobilizations (in the superior, inferior, medial, and lateral directions), paramount in regaining full knee range of motion are initiated the first day postoperatively.

basis for return to activity for patients who desire to return to strenuous sports activities. We especially promote these exercises in younger athletic patients who have an associated ACL reconstruction. 


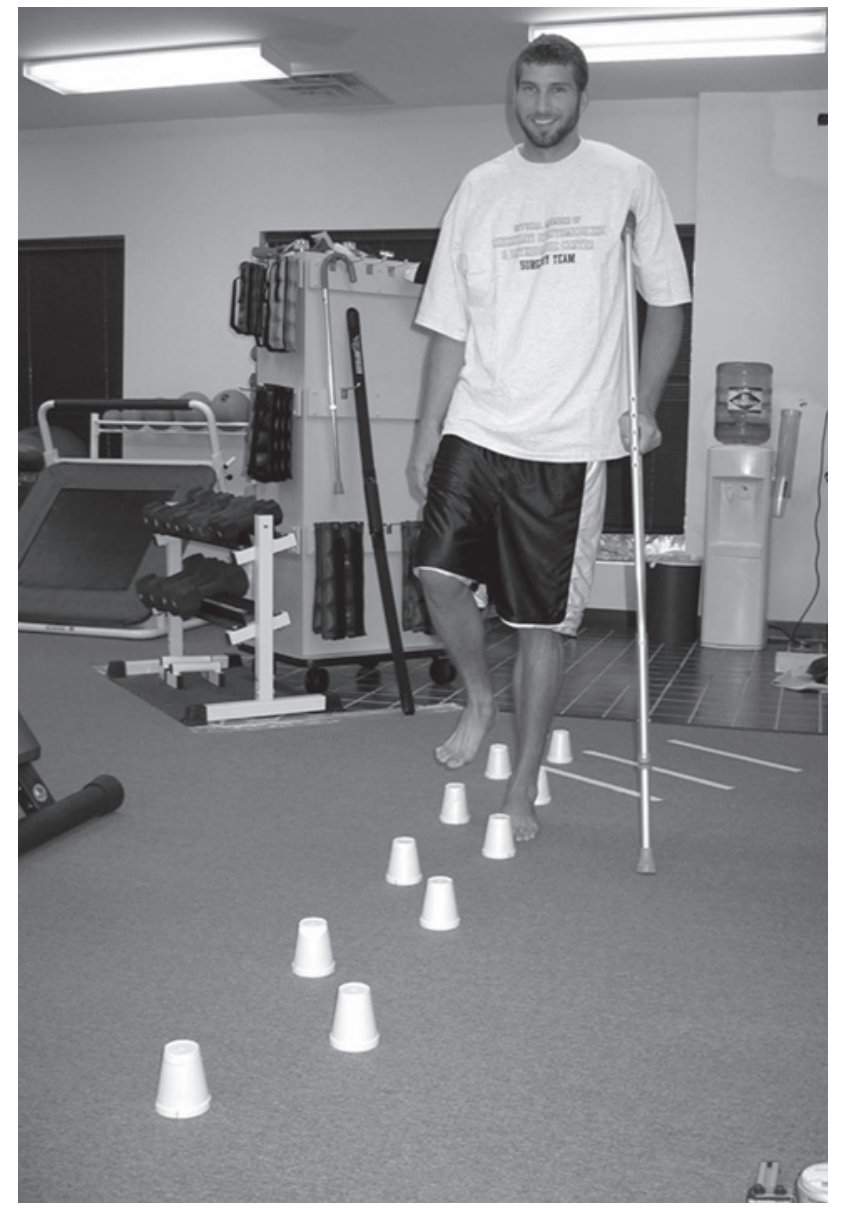

FIGURE 12. Cup walking is used early postoperatively to develop symmetry between the surgical and contralateral limbs, hip and knee flexion, quadriceps control during midstance, hip and pelvic control during midstance, and adequate plantar flexors control during push-off. This exercises also facilitates quadriceps control to prevent knee hyperextension from occurring during gait.

Plyometric training begins with level surface box hopping, done first with both legs and then progresses to single-leg movements as patient confidence improves. Then, vertical box hops are done as previously described in detail. ${ }^{34}$ These activities are typically incorporated after 6 months postoperatively in patients who have had a large peripheral tear or complex repair. In patients who had a radial meniscus repair, this program may be delayed until 9 months postoperatively due to a disruption in the hoop stresses of the meniscus.

In our experience, the majority of patients who undergo meniscal transplantation have noteworthy articular cartilage deterioration and are not candidates for strenuous plyometric training or sports activities. These high-impact loading activities appear to promote earlier failure of the meniscus transplant. Return to light, low-impact activities is our recommendation to these individuals. Adequate patient education and goal setting are critical, and should be initiated first in the preoperative phase and then continued throughout the postoperative period.

\section{Strengthening}

The strengthening program is begun the first day postoperative. Quadriceps isometrics, straight leg raises, and active-assisted knee extension from $90^{\circ}$ to $30^{\circ}$ are done 3 times a day (Table 4). Initially, straight leg raises are performed in the flexion plane only. The patient must achieve a sufficient quadriceps contraction to eliminate an extensor lag before adding straight leg raises in the other 3 planes (abduction, adduction, and extension). These exercises are performed as 3 to 5 sets of 10 repetitions, and this set/repetition rule allows for systematic progression of ankle weights as tolerated.

Weight-bearing exercises are started at weeks 3 to 4. Cup walking is done to facilitate quadriceps control during gait to prevent knee hyperextension from occurring. Toe raises for gastrocsoleus strengthening, wall sits, and mini-squats for quadriceps strengthening are begun in patients who had meniscus repairs. Wall sits (Figure 14) and mini-squats are delayed until 7 to 8 weeks postoperative after meniscal transplantation. These activities should be limited from $0^{\circ}$ to $60^{\circ}$ of flexion to protect the posterior horn of the meniscus. Modifications to reduce patellar pain or increase the difficulty of wall sits have been described previously. ${ }^{34}$ Mini-squats are initially done using the patient's body weight as resistance.

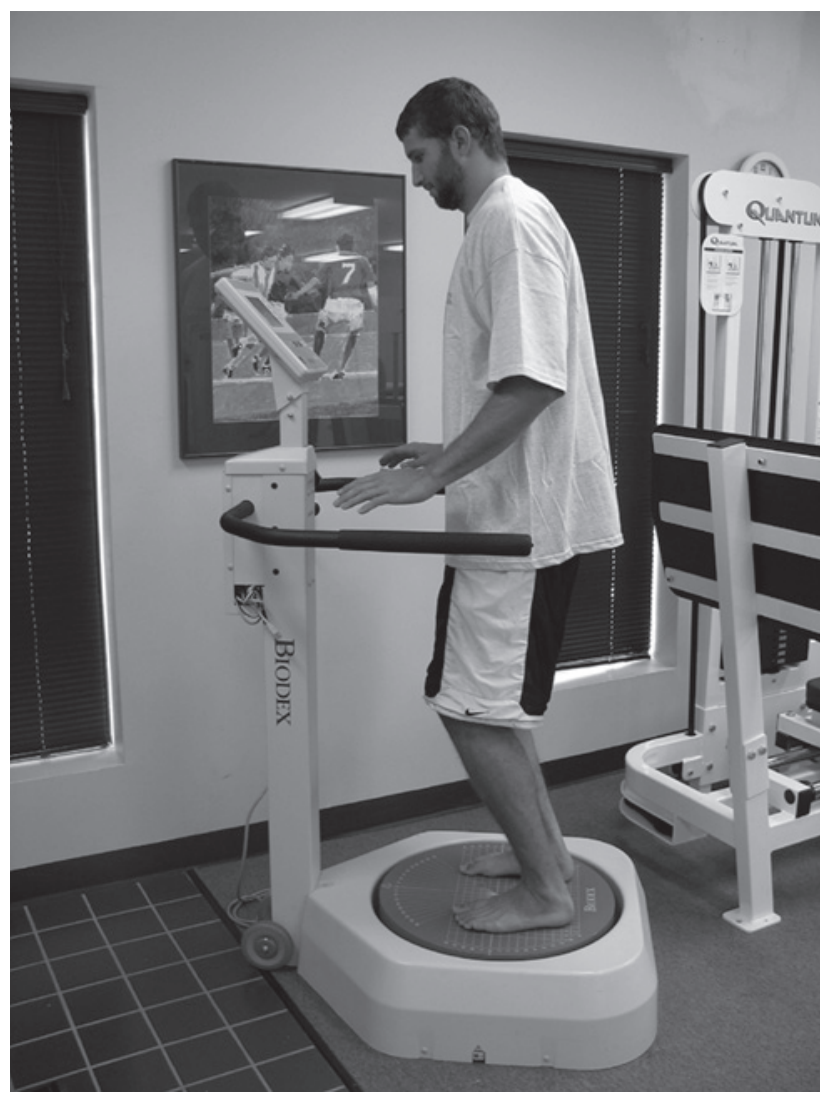

FIGURE 13. A sophisticated balance device (Biodex Corporation, Shirley, NY) provides visual feedback to assist with a variety of balance activities. 


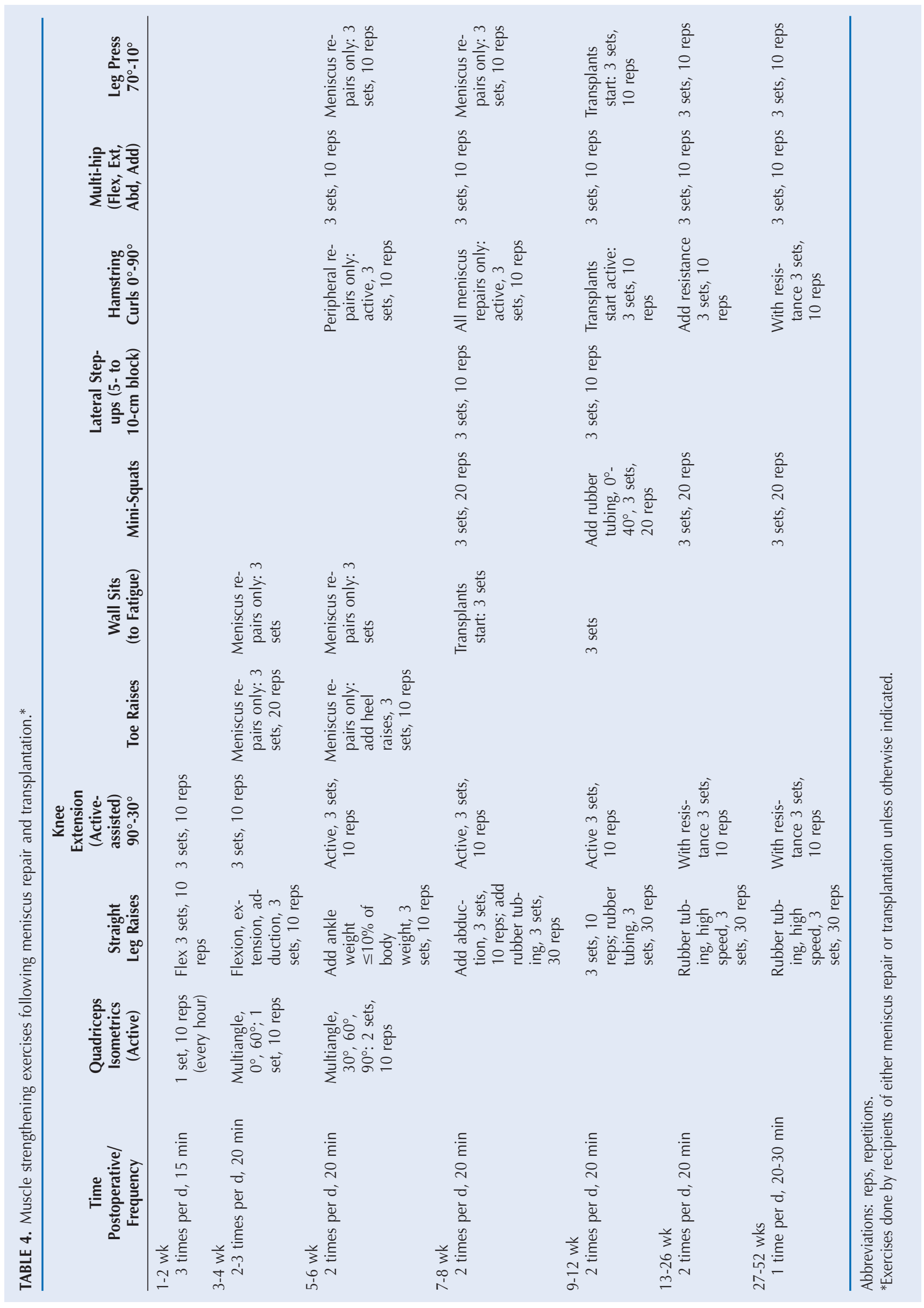




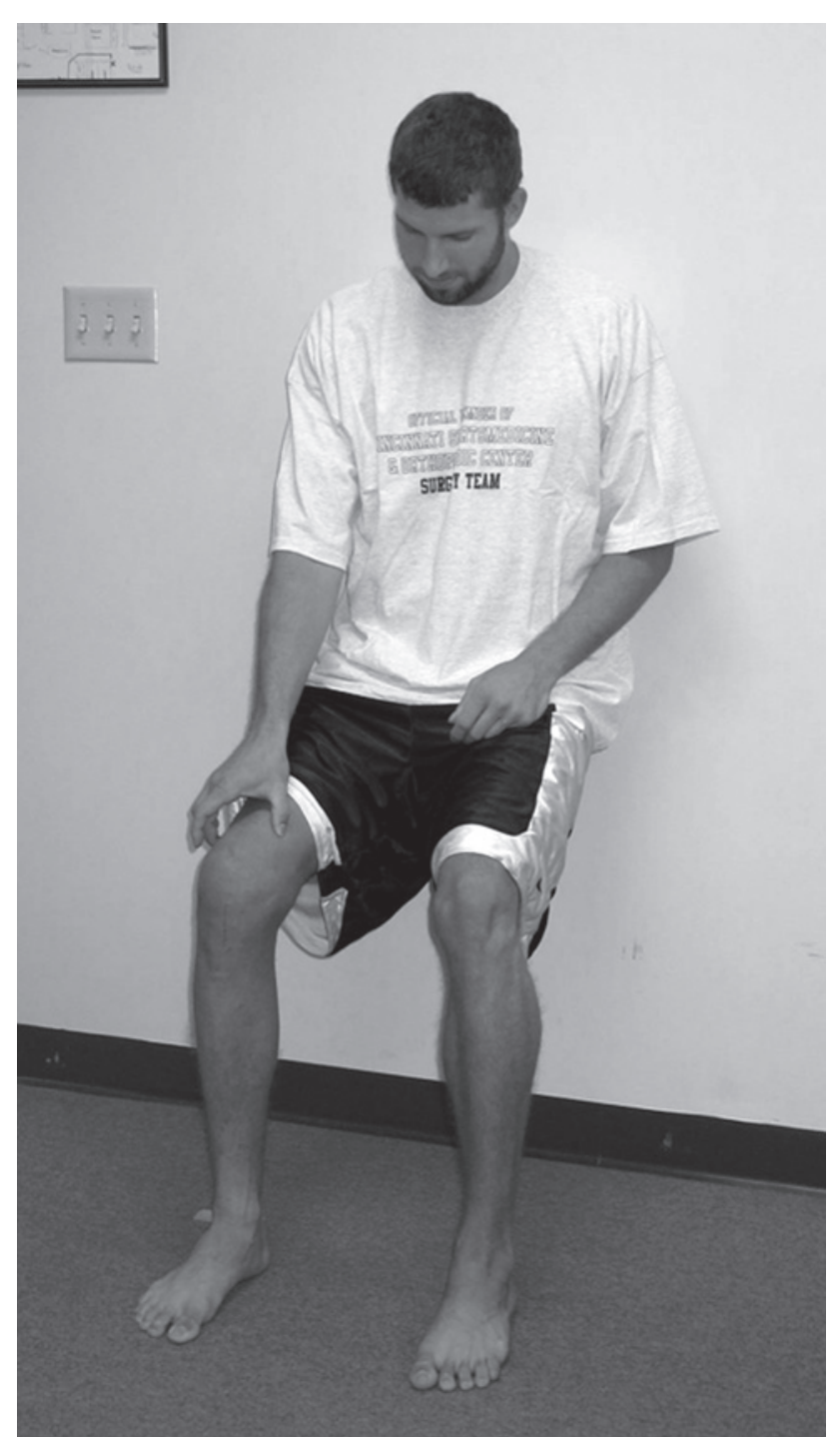

FIGURE 14. Wall sit exercises are begun 7 to 8 weeks postoperative after meniscal transplantation. This exercises is limited from $0^{\circ}$ to $60^{\circ}$ of flexion to protect the posterior horn of the meniscus.

Gradually, Theraband or surgical tubing is used as a resistance mechanism. The depth of the squat is controlled to protect the meniscus repair or transplant and the patellofemoral joint.

Non-weight-bearing strengthening exercises are begun 5 to 6 weeks postoperative (Table 4). Knee extension progressive resistive exercises are initiated from $90^{\circ}$ to $30^{\circ}$ to protect the patellofemoral joint. ${ }^{31}$ Care should be taken to limit deleterious biomechanical stresses on the repair site and suture lines to avoid potential disruption. By keeping the quadriceps exercises in this protected ROM, minimal forces will be placed along peripheral and midsubstance repairs. Progression from ankle weights to machines occurs as the patient progresses the amount of weight in the exercise program. Quadriceps control is critical to the program progression. Hamstring curls from $0^{\circ}$ to $90^{\circ}$ are initiated in patients who had peripheral meniscus repairs at the same time as the quadriceps extensions. Care should be taken to avoid hyperextension, which places tension on the posterior capsule. This exercise is delayed in knees with a complex repair until at least 7 to 8 weeks, and for meniscus transplants, until 9 to 12 weeks postoperative. Isolated resisted hamstring curls are limited in complex repairs and allografts due to the medial hamstring insertion along the posteromedial joint capsule. This limitation is designed to lessen potential traction forces being imposed onto the repair site. Hamstring curls are initiated with Velcro ankle weights, and then progressed to weight machines. The patient is instructed to exercise the involved limb alone, as well as both limbs together.

Because there is increased load placed on the posterior horn of the meniscus after $60^{\circ}$ to $70^{\circ}$ of flexion, a leg press machine may be initiated in the range of $70^{\circ}$ to $10^{\circ}$ at 5 to 6 weeks after all meniscus repairs, and 9 to 12 weeks after transplantation. In all patients, hip abduction and adduction exercises are encouraged. Sidelying straight leg raises are initiated early in the rehabilitation program. Later, when patients have access to the cable column or multi-hip machines, hip flexion and extension are also included in the exercise program. These activities are implemented at 5 to 6 weeks postoperative. Focus of the rehabilitation program should be on muscle strengthening/endurance for the entire lower extremity through the first 4 to 6 months postoperative.

\section{Conditioning}

A cardiovascular program may be initiated as early as 2 to 4 weeks postoperatively if the patient has access to an upper body ergometer (Table 5). Stationary bicycling, with the seat height adjusted to its highest level based on patient body size and use of low resistance level, is begun 7 to 8 weeks postoperatively. If the patient has patellofemoral changes, a recumbent bicycle may be substituted. Additionally, water walking may also be initiated during this timeframe. Walking in water waist high will decrease the impact load to the knee by $50 \%$. To protect the healing meniscus, swimming with straight leg kicking and dry land walking programs are initiated between the ninth and twelfth weeks. At this time, patients that had a meniscus repair may also begin using stair climbing, elliptical cross-trainers, or cross-country ski machines. Protection against high stresses to the patellofemoral joint is required in patients with symptoms or articular cartilage damage. If a stair climbing machine is tolerable, we suggest maintaining a short step and using lower resistance levels. The cardiovascular program should be done at least 3 times a week for 20 to 30 minutes, and the exercise performed to at least $60 \%$ to $85 \%$ of maximal heart rate. 


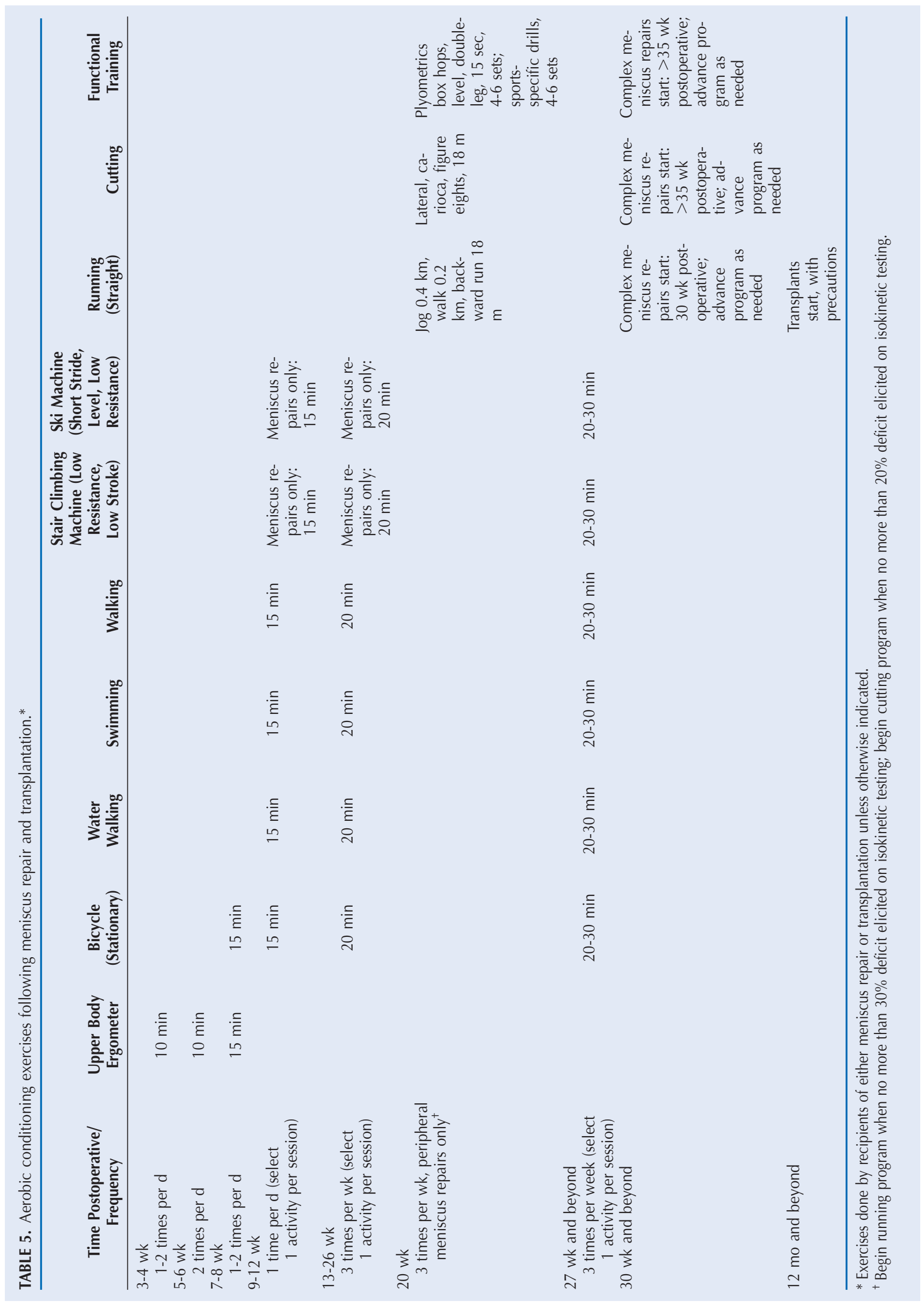




\section{Running and Return to Sports Activities}

A running program is begun at approximately 20 weeks postoperative in patients who had peripheral meniscus repairs and who have no more than a $30 \%$ deficit in average peak torque for the quadriceps and hamstrings on isometric testing performed on a Biodex dynamometer (Biodex Corp, Shirley, NY). Isometric testing is performed at an angle of $60^{\circ}$ of knee flexion. Initial testing at this angle places the knee in a protected position for both the meniscus and patella. Progression to ROM testing at high speeds is important, but the initial goal is to test the integrity of the quadriceps and hamstring musculatures. Other testing parameters worth evaluating include peak torque to body weight ratios, agonistantagonist ratios, and time to peak torque values.

A walk-run combination is initially begun, using running distances of $18,37,55$, and $91 \mathrm{~m}$. Running speed is one quarter to one half of the patient's normal running speed and is gradually progressed. Once the patient can run straight ahead at full speed, lateral and crossover maneuvers are added. Short distances, such as $18 \mathrm{~m}$, are used to work on speed and agility. Side-to-side running over cups may be used to facilitate agility and proprioception. Figure-ofeight and carioca running drills are also useful Sport-specific drills and cutting patterns of $45^{\circ}$ and $90^{\circ}$ angles may be implemented as well, based on the patient's athletic goals. This program is begun at approximately 30 weeks postoperative in patients who had complex meniscus repairs, but is delayed until at least 12 to 24 months postoperatively after transplantation. Repeat Biodex testing is typically performed monthly, progressing from isometric testing for the first 6 months to isokinetic testing at speeds of $180^{\circ}$ and $300^{\circ}$ per second. This testing not only provides the patient with feedback on performance, but also serves to assist the clinician with program progression. Goals for testing should be at least $70 \%$ to begin running and $90 \%$ for full activity for the bilateral torque comparisons, approximately $60 \%$ for agonist-antagonist ratios, and torque-body weight ratios will be based on age, sex, and body weight parameters.

Return to sports activities is based on successful completion of the running and functional training program. Muscle and functional testing should be within normal limits, and a trial of function is encouraged, during which time the patient is monitored for overuse symptoms. Patients who undergo meniscus transplantation are advised to avoid returning to high-impact, strenuous athletics due to the joint damage that is frequently present and the inability of the meniscus transplant to completely restore normal load-sharing function.

\section{CLINICAL OUTCOME STUDIES}

\section{Meniscus Repair}

Results of suture repair of meniscus tears have predictable success rates in terms of resolution of symptoms for tears located in the peripheral region. ${ }^{9,12,19,21,55,57,68}$ Only a few authors have published findings of meniscal repair using arrows and the success rates vary and appear to deteriorate with longer follow-up. ${ }^{2,29,43,48,50}$ In addition, subcutaneous migration of meniscal arrows has been documented by many authors in which further surgery is required to remove the device. ${ }^{10,13,27,33,67}$ Another lessfrequently reported complication associated with meniscal fixators is chondral injury due to either migration of the device or its failure to absorb completely. ${ }^{3,16,30,78}$ Too few data exist in the literature to assess the efficacy of arrows or other meniscal fixators for tears that extend into the central onethird zone. ${ }^{29,84}$

Less predictable results have been reported following suture repair of meniscus tears that extend into the central one-third region. ${ }^{6,12,68,80,86}$ Differences in outcome have occurred due to variations in suture technique and placement along the tear site, postoperative rehabilitation, and concurrent procedures such as ACL reconstruction. We have described the results of these complex repairs in 4 separate investigations, the largest of which involved 198 meniscal repairs in 177 patients. ${ }^{80}$ There were 138 male and 39 females whose average age at the time of the repair was 28 years (range, 9-53 years). An ACL reconstruction was done either with or shortly after the meniscus repair in 126 patients $(71 \%)$. The meniscal repairs were evaluated by clinical examination a mean of 42 months (range, 23-116 months) postoperatively, follow-up arthroscopy (91 repairs) a mean of 18 months (range, 2 to 81 months) postoperatively, or both. The rate of reoperations for meniscal symptoms was $20 \%$. This study's reoperation rate should not be interpreted to be the rate of meniscal failure, but rather the incidence of tibiofemoral joint symptoms in this group of patients. All patients who had tibiofemoral symptoms underwent repeat arthroscopy. There were no complications or limitations of knee motion. The results of this investigation led us to recommend repair of meniscal tears that extend into the central one-third region, especially in patients in their $20 \mathrm{~s}$ and $30 \mathrm{~s}$ and highly competitive athletes. Even though the rate of residual tibiofemoral symptoms was higher than that previously reported for repair of peripheral meniscal tears, ${ }^{12}$ we believe the benefits of a potentially functional meniscus outweigh the risks of reoperation.

We investigated the results of repair of meniscal tears in the central one-third region in middle-aged patients to determine the efficacy of this operation in 
individuals 40 years of age and older. ${ }^{59}$ Thirty repairs in 29 patients were evaluated by clinical examination a mean of 34 months (range, 23-71 months) postoperatively, follow-up arthroscopy (6 repairs) a mean of 24 months (range, 16-36 months) postoperatively, or both. There were 23 men and 6 women whose average age at the time of repair was 45 years (range, 40-58 years). Concurrent ACL reconstructions were performed in 21 patients $(72 \%)$. At follow-up, 26 meniscal repairs $(87 \%)$ were asymptomatic for tibiofemoral joint symptoms. The concomitant ACL reconstructions appeared to influence the rate of asymptomatic meniscal repairs, as $91 \%$ of these knees were free of symptoms at follow-up, compared to $75 \%$ of those who did not require ACL reconstruction. Other authors have demonstrated that an ACL reconstruction done with meniscal repair may protect the repair site through increased anterior-posterior stability and enhance healing from the postoperative hemarthrosis. ${ }^{15,19,41,57}$ There were no complications or limitations of knee motion in our series. This study lead us to conclude that the preservation of meniscal tissue should be attempted whenever possible, regardless of age, in athletically active patients.

In another study, we determined the outcome of repair of meniscal tears in the central one-third region in patients under the age of 20 years. ${ }^{58}$ This represented the first investigation to examine these types of repairs exclusively in this age range. Seventyone repairs in 64 knees were evaluated by clinical examination a mean of 51 months (range, 24-196 months) postoperatively, follow-up arthroscopy (36 repairs) a mean of 18 months (range, 3-60 months) postoperatively, or both. Concomitant ACL reconstructions were done in 47 knees (73\%). At follow-up, 53 repairs $(75 \%)$ were asymptomatic for tibiofemoral joint symptoms and had not required follow-up arthroscopy. Two knees that had an associated ACL reconstruction required a gentle manipulation early postoperatively for a limitation in knee flexion; both regained full ROM.

\section{Meniscus Transplantation}

Since 1984, numerous clinical studies have reported results of meniscus transplantation. ${ }^{14,18,51,61,63,72,85,88,93,94,96,99}$ Differences in tissue processing, secondary sterilization, preservation, operative techniques, and rating schemes make comparisons between studies difficult. ${ }^{17,75}$

Rath et $\mathrm{al}^{73}$ followed 22 patients with cryopreserved meniscal allografts for 2 to 8 years postoperatively. ${ }^{73}$ Eight menisci $(36 \%)$ failed and were removed an average of 31 months postimplantation. Histologic analysis of the torn allografts demonstrated greater than a $50 \%$ reduction in the number of meniscal fibrochondrocytes at the periphery compared with torn native menisci. Verdonk et $\mathrm{al}^{94}$ reported survival rates of 100 patients who had viable (fresh) meniscus transplants. The mean cumulative survival time was similar for medial and lateral transplants (11.6 years). The cumulative survival rates for the medial and lateral transplants at 10 years were $74.2 \%$ and $69.8 \%$, respectively. When a medial meniscus transplant was combined with a high tibial osteotomy, the survival rate increased to $83.3 \%$ at 10 years.

MRI signal intensity alterations of meniscus allografts are frequently reported postoperatively. ${ }^{63,72,85,89,96}$ Potter et $\mathrm{al}^{72}$ followed 29 patients with meniscal allografts 3 to 41 months postoperatively. Increased signal intensity was detected in the posterior horn in 15 knees and peripheral displacement at the body was noted in 11 knees; all of these knees had moderate or severe chondral degeneration. Histologic analysis demonstrated peripheral cellular repopulation, but a central core that was acellular or hypocellular with evidence of disorganized collagen fibers. Knees with mild chondral degeneration had no abnormalities noted in the meniscus allografts and demonstrated superior clinical results compared to those with severe chondral degeneration.

We reported on the outcome of 40 consecutive cryopreserved meniscus transplants that were implanted into 38 patients. ${ }^{63}$ The patients were examined a mean of 40 months (range, 24-69 months) postoperatively. MRI was used to assess 29 of the transplants a mean of 35 months (range, 12-67 months) postoperatively. Transplant height, width, and displacement were measured during full ${ }^{92}$ or partial weight-bearing (loaded) conditions. A classification of meniscal transplant characteristics was developed based on MRI, follow-up arthroscopy, clinical examination, and patient symptoms. Osteochondral autograft transfer (OAT) procedures were performed for femoral condylar defects with the meniscus transplant in 13 knees $(37 \%)$. Knee ligament reconstructions were done before the meniscus transplant in 4 knees and at the same time as the transplant in 4 knees.

Before surgery, 27 patients (77\%) had moderate to severe pain with daily activities; but at follow-up, only 2 patients $(6 \%)$ had pain with daily activities $(P<.0001)$. While all patients had pain specifically located in the meniscectomized tibiofemoral compartment preoperatively (either with daily or sports activities), only 10 had mild tibiofemoral pain at follow-up. The majority of patients $(94 \%)$ believed their knee condition had improved and $77 \%$ were participating in light low-impact sports without problems.

The mean displacement of the transplants in the coronal plane was only $2.2 \pm 1.5 \mathrm{~mm}$ (range, $0-5$ $\mathrm{mm}$ ), which was not considered clinically significant. Intrameniscal signal intensity was normal in 1 , grade 1 in 13 , grade 2 in 11, grade 3 in 3 , and could not be evaluated in 1 knee. One patient had signs of a 
meniscus tear at follow-up. One patient had tibiofemoral joint line pain and increased palpable crepitation compared to the preoperative examination. There were no infections, arthrofibrosis, or limitations of knee motion at follow-up. The reoperation rate for meniscal transplant symptoms was $25 \%$ (10 of 40 meniscus allografts).

In a separate report, we described the results of 96 consecutive irradiated meniscus allografts implanted into 82 patients. ${ }^{61,62}$ Twenty-nine menisci in 28 patients were removed prior to the minimum 2-year follow-up; this left 67 meniscus allografts that were followed 22 to 58 months postoperatively, with MRI and clinical examination. The meniscus transplant failure rate was $6 \%$ ( 1 of 18 knees) in knees with normal or only mild arthrosis on MRI, $45 \%$ (14 of 31 knees) in knees with moderate arthrosis, and $80 \%$ (12 of 15 knees) in knees with advanced arthrosis. The relationship between the meniscus allograft failure rate and increasing severity of joint arthrosis was significant $(P<.001)$. The increase in failure rate was due, we believed, to many factors that were indicators of a disordered remodeling process, including the minimal cellular repopulation of the allograft central core, the disorganized collagen orientation and predominant fibrocyte cellular structure found in several of the failed specimens, and a possible increase in water content and decrease in proteoglycan concentration as reported by Jackson and Simon. ${ }^{39}$ The short-term results of meniscus transplantation are encouraging in terms of reduced knee pain and increased function; however, long-term transplant function and chondroprotective effects remain unknown and require continued investigation.

\section{SUMMARY}

Preservation of meniscal tissue in active individuals provides an overwhelming rationale for the surgeon to make every attempt to repair tears in both the periphery and central one-third avascular zone. The most reliable arthroscopic-assisted technique uses vertical divergent sutures placed every $4 \mathrm{~mm}$ along the length of the tear. Success rates reported after this procedure range from $80 \%$ for complex tears extending into the avascular zone to $98 \%$ for tears located in the periphery, or outer one-third region. For patients in whom meniscus function has been lost from prior meniscectomy, the short-term results of meniscus transplantation are encouraging, as many patients demonstrate improvement in knee function and pain relief in the affected compartment. However, the long-term function of this operation remains questionable, as the transplant appears to undergo remodeling, which results in alterations in collagen fiber architecture required for load-sharing and survival. Patients considering this procedure should be advised that the procedure is not curative in the long-term and additional surgery will most likely be required. A rehabilitation program that implements immediate knee motion, patellar mobilization, and quadriceps-strengthening exercises the first postoperative day after meniscus repair and transplantation is not deleterious to the healing meniscus tissue and prevents knee arthrofibrosis. Precautions are required in limiting high-loading activities, deep knee flexion, and full squatting for at least 4 to 6 months postoperatively.

\section{REFERENCES}

1. Ahmed AM, Burke DL. In-vitro measurement of static pressure distribution in synovial joints--Part I: Tibial surface of the knee. J Biomech Eng. 1983;105:216-225.

2. Albrecht-Olsen $P$, Kristensen $G$, Burgaard $P$, Joergensen $U$, Toerholm C. The arrow versus horizontal suture in arthroscopic meniscus repair. A prospective randomized study with arthroscopic evaluation. Knee Surg Sports Traumatol Arthrosc. 1999;7:268-273.

3. Anderson K, Marx RG, Hannafin J, Warren RF. Chondral injury following meniscal repair with a biodegradable implant. Arthroscopy. 2000;16:749-753.

4. Arnoczky SP, Bullough PG. Healing of knee ligaments and menisci. In: Insall JN, Scott WN, eds. Surgery of the Knee. Philadelphia, PA: W.B. Saunders Company; 2001:457-471.

5. Arnoczky SP, Warren RF. Microvasculature of the human meniscus. Am J Sports Med. 1982;10:90-95.

6. Asahina S, Muneta T, Hoshino A, Niga S, Yamamoto $\mathrm{H}$. Intermediate-term results of meniscal repair in anterior cruciate ligament-reconstructed knees. Am J Sports Med. 1998;26:688-691.

7. Barber FA, Stone RG. Meniscal repair. An arthroscopic technique. J Bone Joint Surg Br. 1985;67:39-41.

8. Barber-Westin SD, Noyes FR, McCloskey JW. Rigorous statistical reliability, validity, and responsiveness testing of the Cincinnati knee rating system in 350 subjects with uninjured, injured, or anterior cruciate ligamentreconstructed knees. Am J Sports Med. 1999;27:402416.

9. Barrett GR, Richardson K, Ruff CG, Jones A. The effect of suture type on meniscus repair. A clinical analysis. Am J Knee Surg. 1997;10:2-9.

10. Bonshahi AY, Hopgood P, Shepard GJ. Migration of a broken meniscal arrow: a case report and review of the literature. Knee Surg Sports Traumatol Arthrosc. 2004;12:50-51.

11. Bullough PG, Munuera L, Murphy J, Weinstein AM. The strength of the menisci of the knee as it relates to their fine structure. J Bone Joint Surg Br. 1970;52:564-567.

12. Buseck MS, Noyes FR. Arthroscopic evaluation of meniscal repairs after anterior cruciate ligament reconstruction and immediate motion. Am J Sports Med. 1991;19:489-494.

13. Calder SJ, Myers PT. Broken arrow: a complication of meniscal repair. Arthroscopy. 1999;15:651-652.

14. Cameron JC, Saha S. Meniscal allograft transplantation for unicompartmental arthritis of the knee. Clin Orthop Relat Res. 1997;164-171.

15. Cannon WD, Jr., Vittori JM. The incidence of healing in arthroscopic meniscal repairs in anterior cruciate ligament-reconstructed knees versus stable knees. Am J Sports Med. 1992;20:176-181. 
16. Cohen SB, Anderson MW, Miller MD. Chondral injury after arthroscopic meniscal repair using bioabsorbable Mitek Rapidloc meniscal fixation. Arthroscopy. 2003;19:E24-26.

17. Cole BJ, Carter TR, Rodeo SA. Allograft meniscal transplantation: background, techniques, and results. Instr Course Lect. 2003;52:383-396.

18. de Boer $\mathrm{HH}$, Koudstaal J. Failed meniscus transplantation. A report of three cases. Clin Orthop Relat Res. 1994;155-162.

19. DeHaven KE, Lohrer WA, Lovelock JE. Long-term results of open meniscal repair. Am J Sports Med. 1995;23:524-530.

20. Dugdale TW, Noyes FR, Styer D. Preoperative planning for high tibial osteotomy. The effect of lateral tibiofemoral separation and tibiofemoral length. Clin Orthop Relat Res. 1992;248-264.

21. Eggli S, Wegmuller H, Kosina J, Huckell C, Jakob RP. Long-term results of arthroscopic meniscal repair. An analysis of isolated tears. Am J Sports Med. 1995;23:715-720.

22. Ellermann A, Siebold R, Buelow JU, Sobau C. Clinical evaluation of meniscus repair with a bioabsorbable arrow: a 2- to 3-year follow-up study. Knee Surg Sports Traumatol Arthrosc. 2002;10:289-293.

23. Fairbank FJ. Knee joint changes after meniscectomy. J Bone Joint Surg. 1948;30B:664-670.

24. Farr J, Meneghini RM, Cole BJ. Allograft interference screw fixation in meniscus transplantation. Arthroscopy. 2004;20:322-327.

25. Fithian DC, Kelly MA, Mow VC. Material properties and structure-function relationships in the menisci. Clin Orthop Relat Res. 1990;19-31.

26. Fukubayashi $\mathrm{T}$, Kurosawa $\mathrm{H}$. The contact area and pressure distribution pattern of the knee. A study of normal and osteoarthrotic knee joints. Acta Orthop Scand. 1980;51:871-879.

27. Ganko A, Engebretsen L. Subcutaneous migration of meniscal arrows after failed meniscus repair. A report of two cases. Am J Sports Med. 2000;28:252-253.

28. Garrett JC. Meniscal transplantation: a review of 43 cases with 2- to 7-year follow-up. Sports Med Arthoscopy Rev. 1993;1:164-167.

29. Gill SS, Diduch DR. Outcomes after meniscal repair using the meniscus arrow in knees undergoing concurrent anterior cruciate ligament reconstruction. Arthroscopy. 2002;18:569-577.

30. Gliatis J, Kouzelis A, Panagopoulos A, Lambiris E. Chondral injury due to migration of a Mitek RapidLoc meniscal repair implant after successful meniscal repair: a case report. Knee Surg Sports Traumatol Arthrosc. 2005; 13:280-282.

31. Grood ES, Suntay WJ, Noyes FR, Butler DL. Biomechanics of the knee-extension exercise. Effect of cutting the anterior cruciate ligament. J Bone Joint Surg Am. 1984;66:725-734.

32. Hantes ME, Kotsovolos ES, Mastrokalos DS, Ammenwerth J, Paessler HH. Arthroscopic meniscal repair with an absorbable screw: results and surgical technique. Knee Surg Sports Traumatol Arthrosc. 2005;13:273-279.

33. Hartley RC, Leung YL. Meniscal arrow migration into the popliteal fossa following attempted meniscal repair: a report of two cases. Knee. 2002;9:69-71.

34. Heckmann TP, Noyes FR, Barber-Westin SD. Autogeneic and allogeneic anterior cruciate ligament rehabilitation. In: Ellenbecker TS, ed. Knee Ligament Rehabilitation. Philadelphia, PA: Churchill Livingstone; 2000:132-150.
35. Henning CE. Arthroscopic repair of meniscus tears. Orthopaedics. 1983;6:113-1132.

36. Henning CE, Clark JR, Lynch MA, Stallbaumer R, Yearout KM, Vequist SW. Arthroscopic meniscus repair with a posterior incision. Instr Course Lect. 1988;37:209-221.

37. Henning CE, Lynch MA. Current concepts of meniscal function and pathology. Clin Sports Med. 1985;4:259265

38. Hurel C, Mertens F, Verdonk R. Biofix resorbable meniscus arrow for meniscal ruptures: results of a 1-year follow-up. Knee Surg Sports Traumatol Arthrosc. 2000;8:46-52.

39. Jackson DW, Simon TM. Biology of meniscal allograft. In: Mow VC, Arnoczky SP, Jackson DW, eds. Knee Meniscus: Basic and Clinical Foundations. New York, NY: Raven Press; 1992:141-152.

40. Jakob RP, Staubli HU, Zuber K, Esser M. The arthroscopic meniscal repair. Techniques and clinical experience. Am J Sports Med. 1988;16:137-142.

41. Jensen NC, Riis J, Robertsen K, Holm AR. Arthroscopic repair of the ruptured meniscus: one to 6.3 years follow up. Arthroscopy. 1994;10:211-214.

42. Johnson RJ, Kettelkamp DB, Clark W, Leaverton P. Factors effecting late results after meniscectomy. J Bone Joint Surg Am. 1974;56:719-729.

43. Jones HP, Lemos MJ, Wilk RM, Smiley PM, Gutierrez R, Schepsis AA. Two-year follow-up of meniscal repair using a bioabsorbable arrow. Arthroscopy. 2002;18:6469.

44. Jones RE, Smith EC, Reisch JS. Effects of medial meniscectomy in patients older than forty years. J Bone Joint Surg Am. 1978;60:783-786.

45. Jorgensen $U$, Sonne-Holm S, Lauridsen F, Rosenklint A. Long-term follow-up of meniscectomy in athletes. A prospective longitudinal study. J Bone Joint Surg Br. 1987;69:80-83.

46. Kettelkamp DB, Jacobs AW. Tibiofemoral contact area-determination and implications. J Bone Joint Surg Am. 1972;54:349-356.

47. Kurosawa H, Fukubayashi T, Nakajima H. Load-bearing mode of the knee joint: physical behavior of the knee joint with or without menisci. Clin Orthop Relat Res. 1980;283-290.

48. Kurzweil PR, Tifford CD, Ignacio EM. Unsatisfactory clinical results of meniscal repair using the meniscus arrow. Arthroscopy. 2005;21:905.

49. Laprell H, Stein V, Petersen W. Arthroscopic all-inside meniscus repair using a new refixation device: a prospective study. Arthroscopy. 2002;18:387-393.

50. Lee GP, Diduch DR. Deteriorating outcomes after meniscal repair using the Meniscus Arrow in knees undergoing concurrent anterior cruciate ligament reconstruction: increased failure rate with long-term followup. Am J Sports Med. 2005;33:1138-1141.

51. Locht RC, Gross AE, Langer F. Late osteochondral allograft resurfacing for tibial plateau fractures. J Bone Joint Surg Am. 1984;66:328-335.

52. McLaughlin JR, Noyes FR. Arthroscopic meniscus repair: recommended surgical techniques for complex meniscal tears. Tech Orthop. 1993;8:129-136.

53. Milachowski KA, Weismeier K, Wirth CJ. Homologous meniscus transplantation. Experimental and clinical results. Int Orthop. 1989;13:1-11.

54. Milachowski KA, Weismeier K, Wirth CJ, et al. Meniscus transplantation - experiment study and first clinical report. Am J Sports Med. 1987;15:626.

55. Mintzer CM, Richmond JC, Taylor J. Meniscal repair in the young athlete. Am J Sports Med. 1998;26:630-633. 
56. Morgan CD, Casscells SW. Arthroscopic meniscus repair: a safe approach to the posterior horns. Arthroscopy. 1986;2:3-12.

57. Morgan CD, Wojtys EM, Casscells CD, Casscells SW. Arthroscopic meniscal repair evaluated by second-look arthroscopy. Am J Sports Med. 1991;19:632-637; discussion 637-638.

58. Noyes FR, Barber-Westin SD. Arthroscopic repair of meniscal tears extending into the avascular zone in patients younger than twenty years of age. Am J Sports Med. 2002;30:589-600.

59. Noyes FR, Barber-Westin SD. Arthroscopic repair of meniscus tears extending into the avascular zone with or without anterior cruciate ligament reconstruction in patients 40 years of age and older. Arthroscopy. 2000;16:822-829.

60. Noyes FR, Barber-Westin SD. A comparison of results in acute and chronic anterior cruciate ligament ruptures of arthroscopically assisted autogenous patellar tendon reconstruction. Am J Sports Med. 1997;25:460-471.

61. Noyes FR, Barber-Westin SD. Irradiated meniscus allografts in the human knee: a two to five year follow-up study. Orthop Transact. 1995;19:417.

62. Noyes FR, Barber-Westin SD, Butler DL, Wilkins RM The role of allografts in repair and reconstruction of knee joint ligaments and menisci. Instr Course Lect. 1998;47:379-396.

63. Noyes FR, Barber-Westin SD, Rankin M. Meniscal transplantation in symptomatic patients less than fifty years old. I Bone Joint Surg Am. 2004:86-A:1392-1404.

64. Noyes FR, Barber-Westin SD, Rankin M. Meniscal transplantation in symptomatic patients less than fifty years old: surgical technique. J Bone Joint Surg Am. 2005;87 Suppl 1 (Pt 2):149-165

65. Noyes FR, Berrios-Torres S, Barber-Westin SD, Heckmann TP. Prevention of permanent arthrofibrosis after anterior cruciate ligament reconstruction alone or combined with associated procedures: a prospective study in 443 knees. Knee Surg Sports Traumatol Arthrosc. 2000;8:196-206.

66. Noyes FR, Mooar PA, Matthews DS, Butler DL. The symptomatic anterior cruciate-deficient knee. Part I: the long-term functional disability in athletically active individuals. J Bone Joint Surg Am. 1983;65:154-162.

67. Oliverson TJ, Lintner DM. Biofix arrow appearing as a subcutaneous foreign body. Arthroscopy. 2000;16:652 655.

68. O'Shea JI, Shelbourne KD. Repair of locked buckethandle meniscal tears in knees with chronic anterior cruciate ligament deficiency. Am J Sports Med. 2003:31:216-220.

69. Petsche TS, Selesnick H, Rochman A. Arthroscopic meniscus repair with bioabsorbable arrows. Arthroscopy. 2002;18:246-253.

70. Pollard ME, Kang Q, Berg EE. Radiographic sizing for meniscal transplantation. Arthroscopy. 1995;11:684 687.

71. Potter HG, Linklater JM, Allen AA, Hannafin JA, Haas SB. Magnetic resonance imaging of articular cartilage in the knee. An evaluation with use of fast-spin-echo imaging. J Bone Joint Surg Am. 1998;80:1276-1284.

72. Potter HG, Rodeo SA, Wickiewicz TL, Warren RF. MR imaging of meniscal allografts: correlation with clinical and arthroscopic outcomes. Radiology. 1996;198:509514.

73. Rath E, Richmond JC, Yassir W, Albright JD, Gundogan F. Meniscal allograft transplantation. Two- to eight-year results. Am J Sports Med. 2001;29:410-414.

74. Rockborn P, Messner K. Long-term results of meniscus repair and meniscectomy: a 13-year functional and radiographic follow-up study. Knee Surg Sports Traumatol Arthrosc. 2000;8:2-10.

75. Rodeo SA. Meniscal allografts--where do we stand? Am J Sports Med. 2001;29:246-261.

76. Roos H, Lauren M, Adalberth T, Roos EM, Jonsson K, Lohmander LS. Knee osteoarthritis after meniscectomy: prevalence of radiographic changes after twenty-one years, compared with matched controls. Arthritis Rheum. 1998;41:687-693.

77. Rosenberg TD, Paulos LE, Parker RD, Coward DB, Scott SM. The forty-five-degree posteroanterior flexion weight-bearing radiograph of the knee. J Bone Joint Surg Am. 1988;70:1479-1483.

78. Ross G, Grabill J, McDevitt E. Chondral injury after meniscal repair with bioabsorbable arrows. Arthroscopy. 2000;16:754-756.

79. Rubins D, Barrett JP, Hayter R. Arthroscopic meniscal allograft transplantation. Arthroscopy. 1993;9:356-357.

80. Rubman MH, Noyes FR, Barber-Westin SD. Arthroscopic repair of meniscal tears that extend into the avascular zone. A review of 198 single and complex tears. Am J Sports Med. 1998;26:87-95.

81. Rubman MH, Noyes FR, Barber-Westin SD. Technical considerations in the management of complex meniscus tears. Clin Sports Med. 1996;15:511-530.

82. Scott GA, Jolly BL, Henning CE. Combined posterior incision and arthroscopic intra-articular repair of the meniscus. An examination of factors affecting healing. J Bone Joint Surg Am. 1986;68:847-861.

83. Spindler KP, McCarty EC, Warren TA, Devin C, Connor JT. Prospective comparison of arthroscopic medial meniscal repair technique: inside-out suture versus entirely arthroscopic arrows. Am J Sports Med. 2003;31:929-934.

84. Steenbrugge F, Verdonk R, Hurel C, Verstraete K. Arthroscopic meniscus repair: inside-out technique vs. Biofix meniscus arrow. Knee Surg Sports Traumatol Arthrosc. 2004;12:43-49.

85. Stollsteimer GT, Shelton WR, Dukes A, Bomboy AL. Meniscal allograft transplantation: a 1- to 5-year follow-up of 22 patients. Arthroscopy. 2000;16:343347.

86. Tenuta JJ, Arciero RA. Arthroscopic evaluation of meniscal repairs. Factors that effect healing. Am J Sports Med. 1994;22:797-802.

87. van Arkel ER, de Boer HH. Human meniscal transplantation. Preliminary results at 2 to 5-year follow-up. J Bone Joint Surg Br. 1995;77:589-595.

88. van Arkel ER, de Boer HH. Survival analysis of human meniscal transplantations. J Bone Joint Surg Br. 2002;84:227-231.

89. van Arkel ER, Goei R, de Ploeg I, de Boer $\mathrm{HH}$. Meniscal allografts: evaluation with magnetic resonance imaging and correlation with arthroscopy. Arthroscopy. 2000;16:517-521.

90. van Trommel MF, Simonian PT, Potter HG, Wickiewicz TL. Arthroscopic meniscal repair with fibrin clot of complete radial tears of the lateral meniscus in the avascular zone. Arthroscopy. 1998;14:360-365.

91. Vande Berg BC, Lecouvet FE, Poilvache $P$, et al Assessment of knee cartilage in cadavers with dualdetector spiral CT arthrography and MR imaging. Radiology. 2002;222:430-436.

92. Vedi V, Williams A, Tennant SJ, Spouse E, Hunt DM, Gedroyc WM. Meniscal movement. An in-vivo study using dynamic MRI. J Bone Joint Surg Br. 1999;81:3741. 
93. Veltri DM, Warren RF, Wickiewicz TL, O'Brien SJ. Current status of allograft meniscal transplantation. Clin Orthop Relat Res. 1994;44-55.

94. Verdonk PC, Demurie A, Almqvist KF, Veys EM, Verbruggen G, Verdonk R. Transplantation of viable meniscal allograft. Survivorship analysis and clinical outcome of one hundred cases. J Bone Joint Surg Am. 2005;87:715-724.

95. Warren RF. Arthroscopic meniscus repair. Arthroscopy. 1985;1:170-172.

96. Wirth CJ, Peters G, Milachowski KA, Weismeier KG, Kohn D. Long-term results of meniscal allograft transplantation. Am J Sports Med. 2002;30:174-181.
97. Yocum LA, Kerlan RK, Jobe FW, et al. Isolated lateral meniscectomy. A study of twenty-six patients with isolated tears. J Bone Joint Surg Am. 1979;61:338-342.

98. Zukor D, Brooks P, Gross AE, et al. Meniscal allografts: experimental and clinical study. Orthop Rev. 1988; 17:522.

99. Zukor DJ, Cameron JC, Brooks PJ, et al. The fate of human meniscal allografts. In: Ewing JW, ed. Articular Cartilage and Knee Joint Function: Basic Science and Arthroscopy. New York, NY: Raven Press; 1990: 